\title{
Systematic characterization and fluorescence threshold strategies for the wideband integrated bioaerosol sensor (WIBS) using size-resolved biological and interfering particles
}

\author{
Nicole J. Savage ${ }^{1}$, Christine E. Krentz ${ }^{1}$, Tobias Könemann² ${ }^{2}$ Taewon T. Han ${ }^{3}$, Gediminas Mainelis ${ }^{3}$, \\ Christopher Pöhlker ${ }^{2}$, and J. Alex Huffman ${ }^{1}$ \\ ${ }^{1}$ University of Denver, Department of Chemistry and Biochemistry, Denver, USA \\ ${ }^{2}$ Max Planck Institute for Chemistry, Multiphase Chemistry and Biogeochemistry Departments, Mainz, Germany \\ ${ }^{3}$ Rutgers, The State University of New Jersey, Department of Environmental Science, New Jersey, USA
}

Correspondence to: J. Alex Huffman (alex.huffman@du.edu) and Nicole J. Savage (nclsavage@ gmail.com)

Received: 25 May 2017 - Discussion started: 28 June 2017

Revised: 8 September 2017 - Accepted: 15 September 2017 - Published: 10 November 2017

\begin{abstract}
Atmospheric particles of biological origin, also referred to as bioaerosols or primary biological aerosol particles (PBAP), are important to various human health and environmental systems. There has been a recent steep increase in the frequency of published studies utilizing commercial instrumentation based on ultraviolet laser/light-induced fluorescence (UV-LIF), such as the WIBS (wideband integrated bioaerosol sensor) or UV-APS (ultraviolet aerodynamic particle sizer), for bioaerosol detection both outdoors and in the built environment. Significant work over several decades supported the development of the general technologies, but efforts to systematically characterize the operation of new commercial sensors have remained lacking. Specifically, there have been gaps in the understanding of how different classes of biological and non-biological particles can influence the detection ability of LIF instrumentation. Here we present a systematic characterization of the WIBS4A instrument using 69 types of aerosol materials, including a representative list of pollen, fungal spores, and bacteria as well as the most important groups of non-biological materials reported to exhibit interfering fluorescent properties. Broad separation can be seen between the biological and non-biological particles directly using the five WIBS output parameters and by taking advantage of the particle classification analysis introduced by Perring et al. (2015). We highlight the importance that particle size plays on observed fluorescence properties and thus in the Perring-style particle classification. We also discuss several particle analysis strategies, including the commonly used fluorescence threshold defined
\end{abstract}

as the mean instrument background (forced trigger; FT) plus 3 standard deviations $(\sigma)$ of the measurement. Changing the particle fluorescence threshold was shown to have a significant impact on fluorescence fraction and particle type classification. We conclude that raising the fluorescence threshold from $\mathrm{FT}+3 \sigma$ to $\mathrm{FT}+9 \sigma$ does little to reduce the relative fraction of biological material considered fluorescent but can significantly reduce the interference from mineral dust and other non-biological aerosols. We discuss examples of highly fluorescent interfering particles, such as brown carbon, diesel soot, and cotton fibers, and how these may impact WIBS analysis and data interpretation in various indoor and outdoor environments. The performance of the particle asymmetry factor (AF) reported by the instrument was assessed across particle types as a function of particle size, and comments on the reliability of this parameter are given. A comprehensive online supplement is provided, which includes size distributions broken down by fluorescent particle type for all 69 aerosol materials and comparing threshold strategies. Lastly, the study was designed to propose analysis strategies that may be useful to the broader community of UV-LIF instrumentation users in order to promote deeper discussions about how best to continue improving UV-LIF instrumentation and results. 


\section{Introduction}

Biological material emitted into the atmosphere from biogenic sources on terrestrial and marine surfaces can play an important role in the health of many living systems and may influence diverse environmental processes (Cox and Wathes, 1995; Pöschl, 2005; Després et al., 2012; Fröhlich-Nowoisky et al., 2016). Bioaerosol exposure has been an increasingly important component of recent interest, motivated by studies linking airborne biological agents and adverse health effects in both indoor and occupational environments (Douwes et al., 2003). Bioaerosols may also impact the environment by acting as giant cloud condensation nuclei or ice nuclei, with an effect on cloud formation and precipitation (Ariya et al., 2009; Delort et al., 2010; Möhler et al., 2007; Morris et al., 2004). Biological material emitted into the atmosphere is commonly referred to as primary biological aerosol particles (PBAP) or bioaerosols. PBAP can include whole microorganisms, such as bacteria and viruses, reproductive entities (fungal spores and pollen), and small fragments of any larger biological material, such as leaves, vegetative detritus, fungal hyphae, or biopolymers, and can represent living, dead, dormant, pathogenic, allergenic, or biologically inert material (Després et al., 2012). PBAP often represent a large fraction of supermicron aerosol, for example up to $65 \%$ by mass in pristine tropical forests, and may also be present in high enough concentrations at submicron sizes to influence aerosol properties (Jaenicke, 2005; Penner, 1994; Pöschl et al., 2010).

Until recently the understanding of physical and chemical processes involving bioaerosols has been limited due to a lack of instrumentation capable of characterizing particles with sufficient time and size resolution (Huffman and Santarpia, 2017). The majority of bioaerosol analysis historically utilized microscopy or cultivation-based techniques. Both are time-consuming, relatively costly, and cannot be utilized for real-time analysis (Griffiths and Decosemo, 1994; Agranovski et al., 2004). Cultivation techniques can provide information about properties of the culturable fraction of the aerosol (e.g., bacterial and fungal spores) but can greatly underestimate the diversity and abundance of bioaerosols because the vast majority of microorganism species are not culturable (Amann et al., 1995; Chi and Li, 2007; Heidelberg et al., 1997). Further, because culture-based methods cannot detect non-viable bioaerosols, information about their chemical properties and allergenicity has been poorly understood.

In recent years, advancements in the chemical and physical detection of bioaerosols have enabled the development of rapid and cost-effective techniques for the real-time characterization and quantification of airborne biological particles (Ho, 2002; Hairston et al., 1997; Huffman and Santarpia, 2017; Sodeau and O'Connor, 2016). One important technique is based on ultraviolet laser/light-induced fluorescence (UV-LIF), originally developed by military research communities for the rapid detection of bio-warfare agents
(BWA) (e.g., Hill et al., 2001, 1999; Pinnick et al., 1995). More recently, UV-LIF instrumentation has been commercialized for application toward civilian research in fields related to atmospheric and exposure science. The two most commonly applied commercial UV-LIF bioaerosol sensors are the wideband integrated bioaerosol sensor (WIBS; University of Hertfordshire, Hertfordshire, UK, now licensed to Droplet Measurement Technologies, Longmont, CO, USA) and the ultraviolet aerodynamic particle sizer (UV-APS; licensed to TSI, Shoreview, MN, USA). Both sensors utilize pulsed ultraviolet light to excite fluorescence from individual particles in a real-time system. The wavelengths of excitation and emission were originally chosen to detect biological fluorophores assumed to be widely present in airborne microorganisms (e.g., tryptophan-containing proteins, NAD(P)H co-enzymes, or riboflavin) (Pöhlker et al., 2012). Significant work was done by military groups to optimize pre-commercial sensor performance toward the goal of alerting to the presence of biological warfare agents such as anthrax spores. The primary objective from this perspective is to positively identify BWAs without being distracted by false positive signals from fluorescent particles in the surrounding natural environment (Primmerman, 2000). From the perspective of basic atmospheric science, however, the measurement goal is often to quantify bioaerosol concentrations in a given environment. So, to a coarse level of discrimination, BWAdetection communities aim to ignore most of what the atmospheric science community seeks to detect. Researchers on such military-funded teams also have often not been able to publish their work in formats openly accessible to civilian researchers, so scientific literature is lean on information that can help UV-LIF users operate and interpret their results effectively. Early UV-LIF bioaerosol instruments have been in use for 2 decades and commercial instruments built on similar concepts are emerging and becoming widely used by scientists in many disciplines. In some cases, however, papers are published with minimal consideration of complexities of the UV-LIF data. This study presents a detailed discussion of several important variables specific to WIBS data interpretation but that can apply broadly to operation and analysis of many similar UV-LIF instruments.

The commercially available WIBS instrument has become one of the most commonly applied instruments toward the detection and characterization of bioaerosol particles in both outdoor and indoor environments. As will be discussed in more detail, the instrument utilizes two wavelengths of excitation (280 and $370 \mathrm{~nm}$ ), the second of which is close to the one wavelength utilized by the UV-APS $(355 \mathrm{~nm})$. Both the WIBS and UV-APS, in various version updates, have been applied to many types of studies regarding outdoor aerosol characterization. For example, they have been important instruments: in the study of ice nuclei (Huffman et al., 2013; Mason et al., 2015; Twohy et al., 2016), toward the understanding of outdoor fungal spore concentrations (Gosselin et al., 2016; Saari et al., 2015a; O'Connor et al., 2015b), to 
investigate the concentration and properties of bioaerosols from long-range transport (Hallar et al., 2011), in tropical aerosol (Gabey et al., 2010; Whitehead et al., 2010, 2016; Huffman et al., 2012; Valsan et al., 2016), in urban aerosol (Huffman et al., 2010; Saari et al., 2015b; Yu et al., 2016), from composting centers (O'Connor et al., 2015b), at high altitude (Crawford et al., 2016; Gabey et al., 2013; Perring et al., 2015; Ziemba et al., 2016), and in many other environments (Healy et al., 2014; Li et al., 2016; O'Connor et al., 2015a). The same instrumentation has been utilized for a number of studies involving the built, or indoor, environment as well (Wu et al., 2016). As a limited set of examples, these instruments have been critical components in the study of bioaerosols in the hospital environment (Lavoie et al., 2015; Handorean et al., 2015) and to study the emission rates of biological particles directly from humans (Bhangar et al., 2016) in school classrooms (Bhangar et al., 2014) and in offices (Xie et al., 2017).

Despite the numerous and continually growing list of studies that utilize commercial UV-LIF instrumentation, only a handful of studies have published results from laboratory work characterizing the operation or analysis of the instruments in detail. For example, Kanaani et al. (2007, 2008, 2009) and Agranovski et al. (2003, 2004, 2005) presented several examples of UV-APS operation with respect to biofluorophores and biological particles. Healy et al. (2012) provided an overview of 15 spore and pollen species analyzed by the WIBS, and Toprak and Schnaiter (2013) discussed the separation of dust from ambient fluorescent aerosol by applying a simple screen of any particles that exhibited fluorescence in one specific fluorescent channel. Hernandez et al. (2016) presented a summary of more than 50 pure cultures of bacteria, fungal spores, and pollen species analyzed by the WIBS and with respect to fluorescent particle type. Fluorescent particles observed in the atmosphere have frequently been used as a lower-limit proxy for biological particles (e.g., Huffman et al., 2010), but it is well known that a number of key particle types of non-biological origin can fluoresce. For example, certain examples of soot, humic and fulvic acids, mineral dusts, and aged organic aerosols can exhibit fluorescent properties, and the effects that these play in the interpretation of WIBS data are unclear (Bones et al., 2010; Gabey et al., 2011; Lee et al., 2013; Pöhlker et al., 2012; Sivaprakasam et al., 2004).

The simplest level of analysis of WIBS data is to provide the number of particles that exceed the minimum detectable threshold in each of the three fluorescence categories. Many papers on ambient particle observations have been written using this data analysis strategy with both the WIBS and UV-APS data. Such analyses are useful and can provide an important first layer of discrimination by fluorescence. To provide more complicated discrimination as a function of observed fluorescence intensity, however, brings associated analysis and computing challenges; i.e., users often must write data analysis code themselves, and process- ing large data sets can push the limits of standard laboratory computers. Discriminating based on fluorescence intensity also requires more detailed investigations into the strategy by which fluorescent thresholds can be applied to define whether a particle is considered fluorescent. Additionally, relatively little attention has been given to the optical properties of nonbiological particles interrogated by the WIBS and to optimize how best to systematically discriminate between biological aerosol of interest and materials interfering with those measurements.

Here we present a comprehensive and systematic laboratory study of WIBS data in order to aid the operation and data interpretation of commercially available UV-LIF instrumentation. This work presents 69 types of aerosol materials, including key biological and non-biological particles, interrogated by the WIBS-4A and shows the relationship of fluorescent intensity and resultant particle type as a function of particle size and asymmetry. A discussion of thresholding strategy is given, with emphasis on how varying strategies can influence characterization of fluorescent properties and either under- or overprediction of fluorescent biological particle concentration.

\section{WIBS instrumentation}

\subsection{Instrument design and operation}

The WIBS uses light scattering and fluorescence spectroscopy to detect, size, and characterize the properties of interrogated aerosols on a single particle basis (instrument model 4A utilized here). Air is drawn into the instrument at a flow rate of $0.3 \mathrm{~L} \mathrm{~min}^{-1}$ and surrounded by a filtered sheath flow of $2.2 \mathrm{~L} \mathrm{~min}^{-1}$. The aerosol sample flow is then directed through a $635 \mathrm{~nm}$, continuous wave (cw) diode laser, which produces elastic scattering measured in both the forward and side directions. Particle sizing in the range of approximately 0.5 to $20 \mu \mathrm{m}$ is detected by the magnitude of the electrical pulse detected by a photomultiplier tube (PMT) located at $90^{\circ}$ from the laser beam. Particles whose measured cw laser-scattering intensity (particle size) exceed userdetermined trigger thresholds will trigger two xenon flash lamps (Xe1 and Xe2) to fire in sequence, approximately $10 \mu$ s apart. The two pulses are optically filtered to emit at 280 and $370 \mathrm{~nm}$, respectively. Fluorescence emitted by a given particle after each excitation pulse is detected simultaneously using two PMT detectors. The first PMT is optically filtered to detect the total intensity of fluorescence in the range $310-400 \mathrm{~nm}$ and the second PMT in the range $420-650 \mathrm{~nm}$. So for every particle that triggers xenon lamp flashes, Xe1 produces a signal in the FL1 (310-400 nm) and FL2 (420$650 \mathrm{~nm}$ ) channels, whereas the Xe2 produces only a signal in the FL3 (420-650 nm) channel because elastic scatter from the Xe2 flash saturates the first PMT. The WIBS-4A has two user-defined trigger thresholds, $\mathrm{T} 1$ and $\mathrm{T} 2$, that define which 
Table 1. Fluorescence and asymmetry factor values of standard PSLs, determined as the peak (mean) of a Gaussian fit applied to a histogram of the signal in each channel. Uncertainties are 1 standard deviation from the Gaussian mean.

\begin{tabular}{lrrrr}
\hline & FL1 & FL2 & FL3 & AF \\
\hline $2 \mu$ m green & $69 \pm 49$ & $1115 \pm 57$ & $214 \pm 29$ & $6 \pm 2$ \\
$2 \mu$ m red & $44 \pm 30$ & $160 \pm 18$ & $28 \pm 13$ & $5 \pm 2$ \\
$2.1 \mu \mathrm{m}$ blue & $724 \pm 111$ & $1904 \pm 123$ & $2045 \pm 6$ & $5 \pm 2$ \\
\hline
\end{tabular}

data will be recorded. Particles producing a scattering pulse from the cw laser that is below the T1 threshold will not be recorded. This enables the user to reduce data collection during experiments with high concentrations of small particles. Particles whose scattering pulse exceeds the T2 threshold will trigger xenon flash lamp pulses for interrogation of fluorescence. Note that the triggering thresholds mentioned here are fundamentally different from the analysis thresholds that will be discussed in detail later.

Forward-scattered light is detected using a quadrant PMT. The detected light intensity in each quadrant are combined using Eq. (1) into an asymmetry factor (AF), where $k$ is an instrument-defined constant, $E$ is the mean intensity measured over the entire PMT, and $E_{i}$ is the intensity measured at the $i$ th quadrant (Gabey et al., 2010).

$\mathrm{AF}=\frac{k\left(\sum_{i=1}^{n}\left(E-E_{i}\right)^{2}\right)^{1 / 2}}{E}$

This parameter relates to a rough estimate of the sphericity of an individual particle by measuring the difference of light intensity scattered into each of the four quadrants. A perfectly spherical particle would theoretically exhibit an AF value of 0 , whereas larger $\mathrm{AF}$ values greater than 0 and less than 100 indicate rod-like particles (Kaye et al., 1991, 2005; Gabey et al., 2010). In practice, spherical PSL (polystyrene latex sphere) particles exhibit a median AF value of approximately 5 (Table 1). It is important to note that the AF parameter is not rigorously a shape factor like that used in other aerosol calculations (DeCarlo et al., 2004; Zelenyuk et al., 2006) and only very roughly relates a measure of particle sphericity.

\subsection{WIBS calibration}

The particle size reported by the internal WIBS calibration introduces significant sizing errors and critically needs to be calibrated before analyzing or reporting particle size. Size calibration was achieved here by using a one-time 27-point calibration curve generated using non-fluorescent PSLs ranging in size from 0.36 to $15 \mu \mathrm{m}$. This calibration involved several steps. For each physical sample, approximately 1000 to 10000 individual particles were analyzed using the WIBS (several minutes of collection). Data collected for each sample were analyzed by plotting a histogram of the side-scatter response reported in the raw data files (FL2_sctpk). A Gaussian curve was fitted to the most prominent mode in the distribution. The median value of the fitted peak for observed side scatter was then plotted against the physical diameter (as reported on the bottle) for each PSL sample. A seconddegree polynomial function was fitted to this curve to create the calibration equation that was used on all laboratory data presented here. The calibration between observed particle size and physical diameter may be affected by wiggles in the optical scattering relationship suggested by Mie theory. These theoretical considerations were not used for the calibrations reported here, and so uncertainties in reported size are expected to increase marginally at larger diameters.

Following the one-time 27-point calibration, the particle sizing response was checked periodically using a five-point calibration. The responses of these calibration checks were within 1 standard deviation unit of each other and so the more comprehensive calibration equation was used in all cases. These quicker checks were performed using non-fluorescent PSLs (Polysciences, Inc., Pennsylvania), including $0.51 \mu \mathrm{m}$ (part number 07307), $0.99 \mu \mathrm{m}$ (07310), $1.93 \mu \mathrm{m}$ (19814), $3.0 \mu \mathrm{m}$ (17134), and $4.52 \mu \mathrm{m}$ (17135).

Fluorescence intensity in each WIBS channel was calibrated using $2.0 \mu \mathrm{m}$ green (G0200), $2.1 \mu \mathrm{m}$ blue (B0200), and $2.0 \mu \mathrm{m}$ red (R0200) fluorescent PSLs (Thermo-Scientific, Sunnyvale, California). For each particle type, a histogram of the fluorescence intensity signal in each channel was fitted with a Gaussian function, and the median intensity was recorded. Periodic checks were performed using the same stock bottles of the PSLs in order to verify that mean fluorescence intensity of each had not shifted more than 1 standard deviation between particle sample types (Table 1). The particle fluorescence standards used present limitations due to variations in fluorescence intensity between stocks of particles and due to fluorophore degradation over time. To improve reliability between instruments, stable fluorescence standards and calibration procedures (e.g., Robinson et al., 2017) will be important.

Voltage gain settings for the three PMTs that produce sizing, fluorescence, and AF values significantly impact measured intensity values and are recorded here for rough comparison of calibrations and analyses to other instruments. The voltage settings used for all data presented here were set according to manufacturer specifications and are as follows: $\mathrm{PMT}_{1}$ (AF) $400 \mathrm{~V}, \mathrm{PMT}_{2}$ (particle sizing and FL1 emission) $450 \mathrm{mV}$, and $\mathrm{PMT}_{3}$ (FL2, FL3 emission) $732 \mathrm{mV}$.

\subsection{WIBS data analysis}

An individual particle is considered to be fluorescent in any one of the three fluorescence channels (FL1, FL2, or FL3) when its fluorescence emission intensity exceeds a given baseline threshold. The baseline fluorescence can be determined by a number of strategies but commonly has been determined by measuring the observed fluorescence in each 


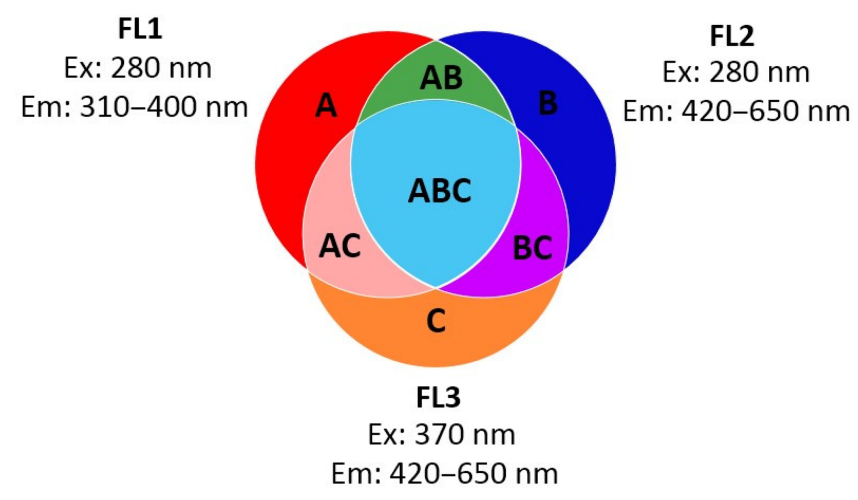

Figure 1. Particle type classification, as introduced by introduced by Perring et al. (2015). Large circles each represent one fluorescence channel (FL1, FL2, FL3). Colored zones represent particle types that each exhibit fluorescence in one, two, or three channels.

channel when the xenon lamps are fired into the optical chamber when devoid of particles. This is referred to as the "forced trigger" (FT) process because the xenon lamp firing is not triggered by the presence of a particle. The instrument background is also dependent on the intensity and orientation of Xe lamps, voltage gains of PMTs, quality of PMTs based on production batch, orientation of optical components (i.e., mirrors in the optical chamber), etc. As a result of these factors, the background or baseline of a given instrument is unique and cannot been used as a universal threshold. All threshold values used in this study are listed in the Supplement Table S1. Fluorescence intensity in each channel is recorded at an approximate FT rate of one value per second for a user-defined time period, typically $30-120 \mathrm{~s}$. The baseline threshold in each channel has typically been determined as the average plus $3 \times$ the standard deviation $(\sigma)$ of FT fluorescence intensity measurement (Gabey et al., 2010), but alternative applications of the fluorescence threshold will be discussed. Particles exhibiting fluorescence intensity lower than the threshold value in each of the three channels are considered to be non-fluorescent. The emission of fluorescence from any one channel is essentially independent of the emission in the other two channels. The pattern of fluorescence measured allows particles to be categorized into seven fluorescent particle types (A, B, C, AB, AC, BC, or ABC) as depicted in Fig. 1 or as completely non-fluorescent (Perring et al., 2015).

Other threshold strategies have also been proposed and will be discussed. For example, Wright et al. (2014) used set fluorescence intensity value boundaries rather than using the standard Gabey et al. (2010) definition that applies a threshold as a function of observed background fluorescence. The Wright et al. (2014) study proposed five separate categories of fluorescent particles (FP1 through FP5). Each definition was determined by selecting criteria for excitation-emission boundaries and observing the empirical distribution of particles in a three-dimensional space (FL1 vs. FL2 vs. FL3).
For the study reported here, only the FP3 definition was used for comparison, because Wright et al. (2014) postulated the category as being enriched with fungal spores during their ambient study and because they observed that these particles scaled more tightly with observed ice nucleating particles. The authors classified a particle in the FP3 category if the fluorescence intensity in FL1 $>1900$ arbitrary units (a.u.) and between 0 and 500 a.u. for each FL2 and FL3.

\section{Materials and methods}

\subsection{Aerosol materials}

\subsubsection{Table of materials}

All materials utilized, including the vendors and sources from where they were acquired, have been listed in Supplement Table S1, organized into broad particle type groups: biological material (fungal spores, pollen, bacteria, and biofluorophores) and non-biological material (dust, humic-like substances or HULIS, polycyclic aromatic hydrocarbons or PAHs, combustion soot and smoke, and common household fibers). Combustion soot and smoke are grouped into one set of particles analyzed and are hereafter referred to as "soot" samples. It is important to note that all particle types analyzed here essentially represent "fresh" emissions. It is unclear how atmospheric aging might impact their surface chemical properties or how their observed fluorescence properties might evolve over time.

\subsubsection{Brown carbon synthesis}

Three different brown carbon solutions were synthesized using procedures described by Powelson et al. (2014): (Rxn 1) methylglyoxal + glycine, $($ Rxn 2$)$ glycolaldehyde + methylamine, and (Rxn 3) glyoxal + ammonium sulfate. These reactions were chosen because the reaction products were achievable using bulk-phase aqueous chemistry and did not require more complex laboratory infrastructure. They represent three examples of reactions possible in cloud water using small, water-soluble carbonyl compounds mixed with either ammonium sulfate or a primary amine (Powelson et al., 2014). A large number of reaction pathways exist to produce atmospheric brown carbon, however, and the products analyzed here are intended primarily to introduce the possible importance of brown carbon droplets and coatings to fluorescence-based aerosol detection (Huffman et al., 2012).

Reactions conditions were reported previously, so only specific concentration and volumes used here are described. All solutions described are aqueous and were dissolved into 18.2 $\mathrm{M} \Omega$ water (Millipore Sigma; Denver, CO). For reaction $1,25.0 \mathrm{~mL}$ of $0.5 \mathrm{M}$ methylglyoxal solution was mixed with $25 \mathrm{~mL}$ of $0.5 \mathrm{M}$ glycine solution. For reaction $2,5.0 \mathrm{~mL}$ of $0.5 \mathrm{M}$ glyoxal trimer dihydrate solution was mixed with $5.0 \mathrm{~mL}$ of $0.5 \mathrm{M}$ ammonium sulfate solution. For reaction 3, 
$10.0 \mathrm{~mL}$ of $0.5 \mathrm{M}$ glycolaldehyde solution was mixed with $10.0 \mathrm{~mL}$ of $0.5 \mathrm{M}$ methylamine solution. The $\mathrm{pH}$ of the solutions was adjusted to approximately $\mathrm{pH} 4$ by adding $1 \mathrm{M}$ oxalic acid in order for the reaction to follow the appropriate chemical mechanism (Powelson et al., 2014). The solutions were covered with aluminum foil and stirred at room temperature for 8,4 , and 4 days for reactions 1,2 , and 3 , respectively. Solutions were aerosolized via the liquid aerosolization method described in Sect. 3.2.4.

\subsection{Aerosolization methods}

\subsubsection{Fungal spore growth and aerosolization}

Fungal cultures were inoculated onto sterile, disposable polystyrene plates (Carolina, Charlotte, NC) filled with agar growth media consisting of malt extract medium mixed with $0.04 \mathrm{M}$ of streptomycin sulfate salt (S6501, Sigma-Aldrich) to suppress bacterial colony growth. Inoculated plates were allowed to mature and were kept in a sealed Plexiglas box for 3-5 weeks until aerosolized. Air conditions in the box were monitored periodically and were consistently $25-27^{\circ} \mathrm{C}$ and $70 \%$ relative humidity.

Fungal cultures were aerosolized inside an environmental chamber constructed from a re-purposed home fish tank (Aqueon Glass Aquarium, 5237965). The chamber has glass panels with dimensions $20.5 \mathrm{~L} \times 10.25 \mathrm{H} \times 12.5 \mathrm{~W}$ in. (Supplement Fig. S1). Soft rubber beading seals the top panel to the walls, allowing isolation of air and particles within the chamber. Two tubes are connected to the lid. The first tube delivers pressurized and particle-free air through a bulkhead connection, oriented by plastic tubing (Loc-Line coolant hose, 0.64 in. outer diameter) and a flat nozzle. The second tube connects $0.75 \mathrm{in}$. internal diameter conductive tubing (Simolex Rubber Corp., Plymouth, MI) for aspiration of fungal aerosol, passing it through a bulkhead fitting and into tubing directed toward the WIBS. Aspiration tubing is oriented such that a gentle $90^{\circ}$ bend brings aerosol up vertically through the top panel.

For each experiment, an agar plate with a mature fungal colony was sealed inside the chamber. A thin, wide nozzle was positioned so that the delivered air stream approximated a blade of air that approached the top of the spore colony at a shallow angle in order to eject spores into a roughly horizontal trajectory. The sample collection tube was positioned immediately past the fungal plate to draw in aerosolized fungal particles. Filtered room air was delivered by a pump through the aerosolizing flow at approximately $9-15 \mathrm{~L} \mathrm{~min}^{-1}$, varied within each experiment to optimize measured spore concentration. Sample flow was $0.3 \mathrm{~L} \mathrm{~min}^{-1}$ into the WIBS and excess input flow was balanced by outlet through a particle filter connected through a bulkhead on the top plate.

Two additional rubber septa in the top plate allow the user to manipulate two narrow metal rods to move the agar plate once spores were depleted from a given region of the colony.
After each spore experiment, the chamber and tubing was evacuated by pumping for $15 \mathrm{~min}$, and all interior surfaces were cleaned with isopropanol to avoid contamination between samples.

\subsubsection{Bacterial growth and aerosolization}

All bacteria were cultured in nutrient broth (Becton, Dickinson and Company, Sparks, MD) for $18 \mathrm{~h}$ in a shaking incubator at $30^{\circ} \mathrm{C}$ for Bacillus atrophaeus (ATCC 49337, American Type Culture Collection, MD), $37^{\circ} \mathrm{C}$ for Escherichia coli (ATCC 15597), and $26^{\circ} \mathrm{C}$ Pseudomonas fluorescens (ATCC 13525). Bacterial cells were harvested by centrifugation at $7000 \mathrm{rpm}(6140 \mathrm{~g})$ for $5 \mathrm{~min}$ at $4{ }^{\circ} \mathrm{C}$ (BR4, Jouan Inc., Winchester, VA) and washed four times with autoclave-sterilized deionized water (Millipore Corp., Billerica, MA) to remove growth media. The final liquid suspension was diluted with sterile deionized water, transferred to a polycarbonate jar and aerosolized using a three-jet Collison Nebulizer (BGI Inc., Waltham, MA) operated at $5 \mathrm{~L} \mathrm{~min}^{-1}$ (pressure of $12 \mathrm{psi}$ ). The polycarbonate jar was used to minimize damage to bacteria during aerosolization (Zhen et al., 2014). The tested airborne cell concentration was about $\sim 10^{5}$ cells $\mathrm{L}^{-1}$ as determined by an optical particle counter (model 1.108, Grimm Technologies Inc., Douglasville, GA). Bacterial aerosolization took place in an experimental system containing a flow control system, a particle generation system, and an airparticle mixing system introducing filtered air at $61 \mathrm{~L} \mathrm{~min}^{-1}$ as described by Han et al. (2015).

\subsubsection{Powder aerosolization}

Dry powders were aerosolized by mechanically agitating material by one of several methods mentioned below and passing filtered air across a vial containing the powder. For each method, approximately $2.5-5.0 \mathrm{~g}$ of sample was placed in a $10 \mathrm{~mL}$ glass vial. For most samples (method P1), a stir bar was added, and the vial was placed on a magnetic stir plate. Two tubes were connected through the lid of the vial. The first tube connected a filter, allowing particle-free air to enter the vessel. The second tube connected the vial through approximately $33 \mathrm{~cm}$ of conductive tubing $(0.25 \mathrm{in}$. inner diam.) to the WIBS for sample collection.

The setup was modified (method P2) for a small subset of samples whose solid powder was sufficiently fine to produce high number concentrations of particles (e.g., $>200 \mathrm{~cm}^{-3}$ ) and that contained enough submicron aerosol material to risk coating the internal flow path and damaging optical components of the instrument. In this case, the same small vial with powder and stir bar was placed in a larger reservoir $(\sim 0.5 \mathrm{~L})$, but without the vial's lid. The lid of the larger reservoir was connected to filtered air input and an output connection to the instrument. The additional container volume allowed for greater dilution of aerosol before sampling into the instrument. 
Some powder samples produced consistent aerosol number concentration even without stirring. For these samples, 2.5-5.0 g of material was placed in a small glass vial and set under a laboratory fume hood (method P3). Conductive tubing was held in place at the opening of the vial using a clamp, and the opposite end was connected to the instrument with a flow rate of $0.3 \mathrm{~L} \mathrm{~min}^{-1}$. The vial was tapped by hand or with a hand tool, physically agitating the material and aerosolizing the powder.

\subsubsection{Liquid aerosolization}

Disposable, plastic medical nebulizers (Allied Healthcare, St. Louis, MO) were used to aerosolize liquid solutions and suspensions. Each nebulizer contains a reservoir where the solution is held. Pressurized air is delivered through a capillary opening on the side, reducing static pressure and, as a result, drawing fluid into the tube. The fluid is broken up by the air jet into a dispersion of droplets, where most of the droplets are blown onto the internal wall of the reservoir, and droplets remaining aloft are entrained into the sample stream. Output from the medical nebulizer was connected to a dilution chamber (aluminum enclosure, $0.5 \mathrm{~L}$ ), allowing the droplets to evaporate in the system before particles enter the instrument for detection.

\subsubsection{Smoke generation}

Wood and cigarette smoke samples were aerosolized through combustion. Each sample was ignited separately using a personal butane lighter while held underneath a laboratory fume hood. Once the flame from the combusting sample was naturally extinguished, the smoldering sample was waved at a height $\sim 5 \mathrm{~cm}$ above the WIBS inlet for 3-5 min during sampling.

\subsection{Pollen microscopy}

Pollen samples were aerosolized using the dry powder vial (P1, P2) and tapping (P3) methods detailed above. Samples were also collected by impaction onto a glass microscope slide for visual analysis using a home-built, single-stage impactor with $D_{50}$ cut $\sim 0.5 \mu \mathrm{m}$ at flow rate $1.2 \mathrm{~L} \mathrm{~min}^{-1}$. Pollen was analyzed using an optical microscope (VWR model 89404-886) with a 40× objective lens. Images were collected with an AmScope complementary metal-oxide semiconductor camera (model MU800, 8 megapixels).

\section{Results}

\subsection{Broad separation of particle types}

The WIBS is routinely used as an optical particle counter applied to the detection and characterization of fluorescent biological aerosol particles. Each interrogated particle pro- vides five discreet pieces of information: fluorescence emission intensity in each of the three detection channels (FL1, FL2, and FL3), particle size, and particle asymmetry. Thus, a thorough summary of data from aerosolized particles would require the ability to show statistical distributions in five dimensions. As a simple, first-order representation of the most basic summary of the 69 particle types analyzed, Fig. 2 and Table 2 show median values for each of the five data parameters plotted in three plot styles (columns of panels in Fig. 2).

For the sake of WIBS analysis, each pollen type was broken into two size categories, because it was observed that most pollen species exhibited two distinct size modes. The largest size mode peaked above $10 \mu \mathrm{m}$ in all cases and often saturated the sizing detector (see also fraction of particles that saturated particle detector for each fluorescence channel in Table 2). This was interpreted to be intact pollen. A broad mode also usually appeared at smaller particle diameters for some pollen species, suggesting that pollen grains had ruptured during dry storage or through the mechanical agitation process. This hypothesis was supported by optical microscopy through which a mixture of intact pollen grains and ruptured fragments was observed (Fig. S2). For the purposes of this investigation, the two modes were separated at the minimum point in the distribution between modes in order to observe optical properties of the intact pollen and pollen fragments separately. The list number for each pollen (Tables 2, S1 in the Supplement) is consistent for the intact and fragmented species, though not all pollen exhibited obvious pollen fragments.

The WIBS was developed primarily to discriminate biological from non-biological particles, and the three fluorescence channels broadly facilitate this separation. Biological particles, i.e., pollen, fungal spores, and bacteria (top row of Fig. 2), each show strong median fluorescence signal in at least one of the three channels. In general, all fungal spores sampled (blue dots) show fluorescence in the FL1 channel with lower median emission in FL2 and FL3 channels. Both the fragmented (pink dots) and intact (orange dots) size fractions of pollen particles showed high median fluorescence emission intensity in all channels, varying by species and strongly as a function of particle size. The three bacterial species sampled (green dots) showed intermediate median fluorescence emission in the FL1 channel and very low median intensity in either of the other two channels. To support the understanding of whole biological particles, pure molecular components common to biological material were aerosolized separately and are shown as the second row of Fig. 2. Each of the biofluorophores chosen shows relatively high median fluorescence intensity, again varying as a function of size. Key biofluorophores such as NAD, riboflavin, tryptophan, and tyrosine are individually labeled in Fig. 2d. Supermicron particles of these pure materials would not be expected in a real-world environment but are present as dilute components of complex biological material and are useful here for comparison. In general, the spectral properties sum- 

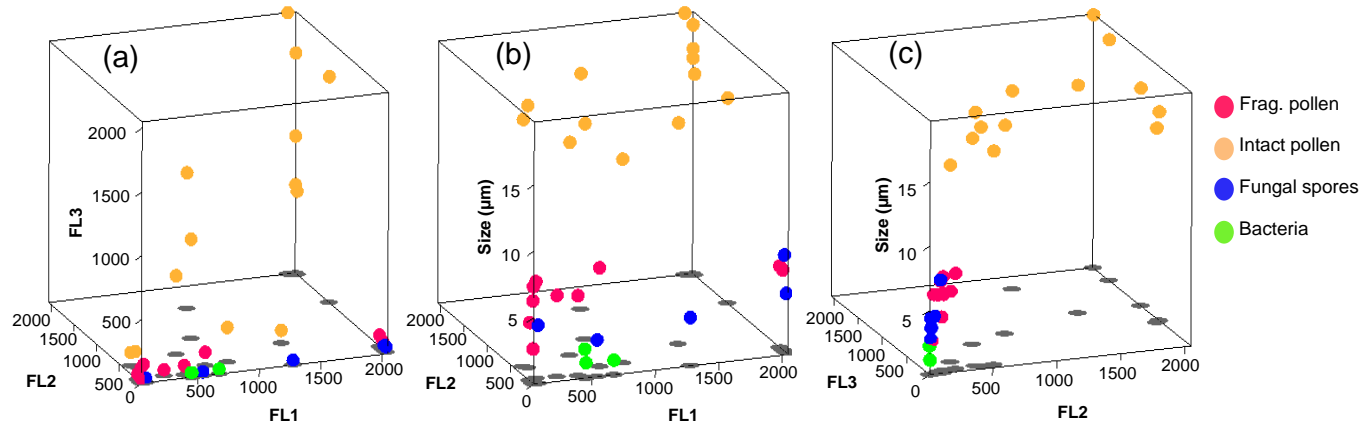

Bacteria
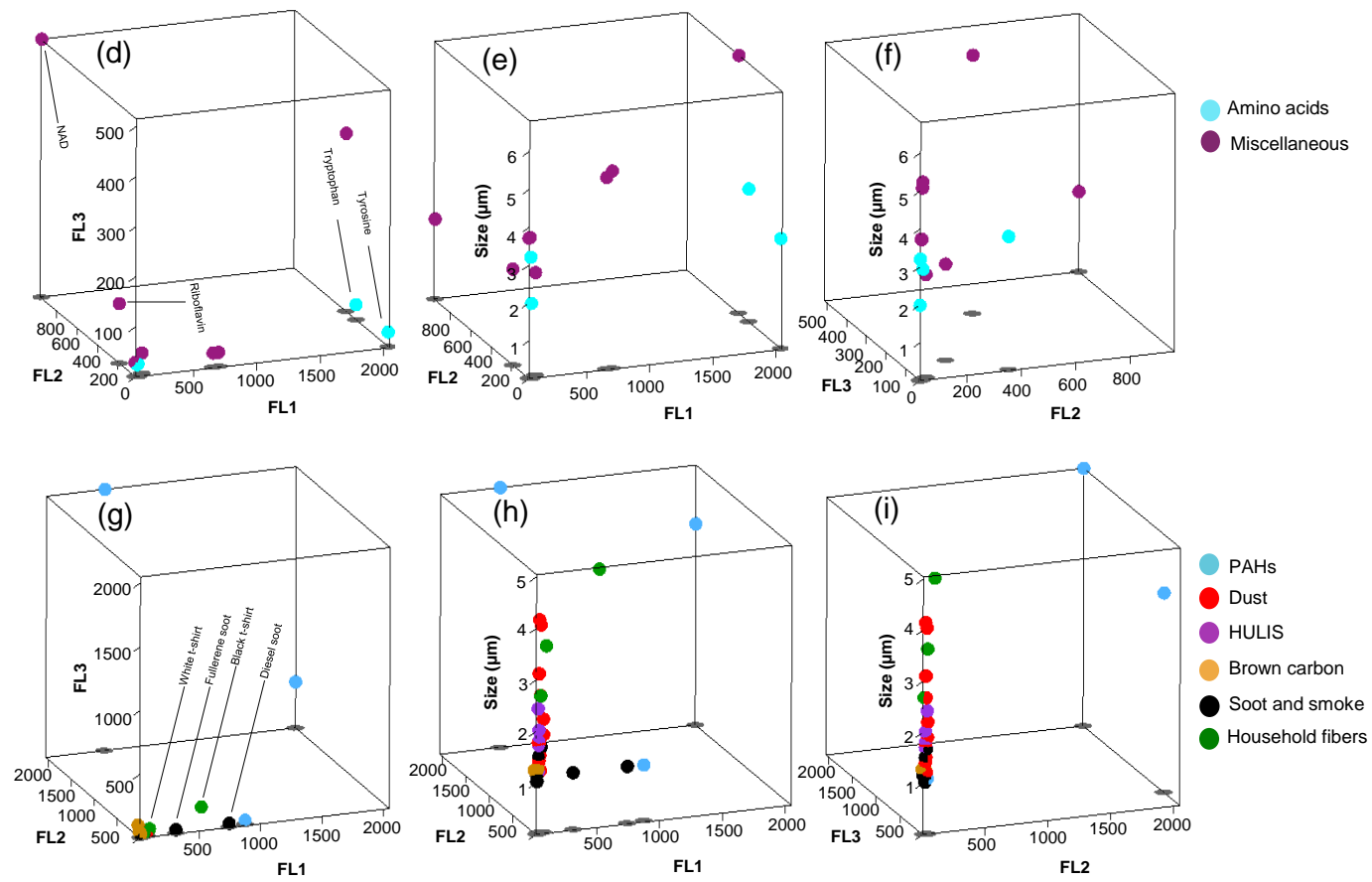

Figure 2. Representations including four of the five parameters recorded by the WIBS: FL1, FL2, FL3, and particle size. Biological material types (a-c), bio-fluorophores (d-f), and non-biological particle types (g-i). Data points represent median values. Gray ovals are shadows (cast directly downward onto the bottom plane) included to help reader with 3-D representation. Tags in (g) and (d) used to differentiate particles of specific importance within text.

marized here match well with fluorescence excitation emission matrices presented by Pöhlker et al. $(2012,2013)$

In contrast to the particles of biological origin, a variety of non-biological particles were aerosolized in order to elucidate important trends and possible interferences. The majority of non-biological particles shown in the bottom row of Fig. 2 show little to no median fluorescence in each channel and are therefore difficult to differentiate from one another in the figure. For example, Fig. $2 \mathrm{~g}$ (lower left) shows the median fluorescence intensity of six different groups of particle types (33 total dots) but almost all overlap at the same point at the graph origin. The exceptions to this trend include the PAHs (blue dots), common household fibers (green), and several types of combustion soot (black dots). The fluorescent properties of PAHs are well known both in basic chemical literature and as observed in the atmosphere (Niessner and Krupp, 1991; Finlayson-Pitts and Pitts, 1999; Panne et al., 2000; Slowik et al., 2007). PAHs can be produced by a number of anthropogenic sources and are emitted in the exhaust from vehicles and other combustion sources as well as from biomass burning (Aizawa and Kosaka, 2010, 2008; Abdel-Shafy and Mansour, 2016; Lv et al., 2016). PAHs alone exhibit high fluorescence quantum yields (Pöhlker et al., 2012; Mercier et al., 2013) but as pure materials are not usually present in high concentrations at sizes large enough $(>0.8 \mu \mathrm{m})$ to be detected by the WIBS. Highly fluorescent PAH molecules are also common constituents of other complex particles, including soot particle agglomerates. It has been observed that the fluorescent emission of PAH constituents on soot particles can be weak due to quenching from the bulk material (Panne et al., 2000). Several examples of soot particles shown in Fig. $2 \mathrm{~g}$ are fluorescent in FL1 
Table 2. Median values for each of the five data parameters, along with percent of particles that saturate fluorescence detector in each fluorescence channel. Uncertainty (as 1 standard deviation, $\sigma$ ) listed for particle size and asymmetry factor (AF). Only a sub-selection of pollen are characterized as fragmented pollen because not all pollen presented the smaller size fraction or fluorescence characteristics that represent fragments.

\begin{tabular}{|c|c|c|c|c|c|c|c|c|c|c|}
\hline \multicolumn{2}{|c|}{ Materials } & FL1 & $\begin{array}{r}\text { FL1 Sat } \\
\%\end{array}$ & FL2 & $\begin{array}{r}\text { FL2 Sat } \\
\%\end{array}$ & FL3 & $\begin{array}{r}\text { FL3 Sat } \\
\%\end{array}$ & $\begin{array}{r}\text { Size } \\
(\mu \mathrm{m})\end{array}$ & $\mathrm{AF}$ & $\begin{array}{l}\text { Aerosolization } \\
\text { method }\end{array}$ \\
\hline \multicolumn{11}{|c|}{ Biological materials } \\
\hline \multicolumn{11}{|c|}{ Pollen } \\
\hline \multicolumn{11}{|c|}{ Intact pollen } \\
\hline 1 & Urtica dioica (stinging nettle) & 2047.0 & 99.2 & 2047.0 & 99.4 & 1072.0 & 9.9 & $16.9 \pm 2.2$ & $18.5 \pm 8.3$ & Powder (P1) \\
\hline 2 & Artemisia vulgaris (common mugwort) & 1980.0 & 48.3 & 2047.0 & 99.7 & 2047.0 & 90.3 & $19.7 \pm 1.0$ & $14.2 \pm 7.6$ & Powder (P1) \\
\hline 3 & Castanea sativa (European chestnut) & 830.0 & 19.3 & 258.0 & 2.9 & 269.0 & 0.8 & $15.3 \pm 1.7$ & $17.0 \pm 9.5$ & Powder (P1) \\
\hline 4 & Corylus avellana (hazel) & 1371.0 & 44.4 & 532.0 & 5.6 & 99.0 & 2.8 & $16.6 \pm 2.1$ & $24.2 \pm 12.6$ & Powder (P1) \\
\hline 5 & Taxus baccata (common yew) & 525.0 & 0.4 & 561.0 & 0.2 & 615.0 & 0.0 & $16.0 \pm 1.3$ & $22.2 \pm 10.0$ & Powder (P1) \\
\hline 6 & Rumex acetosella (sheep sorrel) & 2047.0 & 73.5 & 2047.0 & 55.1 & 693.0 & 2.7 & $16.2 \pm 2.0$ & $21.7 \pm 10.8$ & Powder (P1) \\
\hline 7 & Olea europaea (European olive tree) & 131.0 & 1.1 & 395.0 & 0.4 & 119.0 & 0.0 & $19.7 \pm 1.2$ & $17.7 \pm 7.6$ & Powder (P1) \\
\hline 8 & Alnus glutinosa (black alder) & 109.0 & 3.3 & 432.0 & 1.2 & 102.0 & 0.9 & $18.6 \pm 1.7$ & $15.8 \pm 8.5$ & Powder (P1) \\
\hline 9 & Phleum pratense (Timothy grass) & 2047.0 & 100.0 & 2012.0 & 49.8 & 651.0 & 1.9 & $15.1 \pm 1.7$ & $24.1 \pm 12.2$ & Powder (P1) \\
\hline 10 & Populus alba (white poplar) & 2047.0 & 95.9 & 2047.0 & 92.2 & 1723.0 & 39.2 & $18.7 \pm 1.9$ & $21.2 \pm 10.4$ & Powder (P1) \\
\hline 11 & Taraxacum officinale (common dandelion) & 2047.0 & 99.1 & 1309.0 & 21.8 & 1767.0 & 44.2 & $15.4 \pm 1.8$ & $22.2 \pm 11.9$ & Powder (P1) \\
\hline 12 & Amaranthus retroflexus (redroot amaranth) & 980.0 & 36.7 & 1553.0 & 36.7 & 1061.0 & 18.0 & $17.7 \pm 2.2$ & $19.4 \pm 12.1$ & Powder (P1) \\
\hline 13 & Aesculus hippocastanum (horse chestnut) & 762.0 & 23.5 & 876.0 & 23.5 & 776.0 & 23.5 & $16.2 \pm 2.0$ & $22.2 \pm 13.4$ & Powder (P1) \\
\hline 14 & Lycopodium (clubmoss) & 40.0 & 0.1 & 32.0 & 0.0 & 27.0 & 0.0 & $3.9 \pm 1.86$ & $24.5 \pm 15.9$ & Powder (P1) \\
\hline \multicolumn{11}{|c|}{ Fragment pollen } \\
\hline 3 & Castanea sativa (European chestnut) & 74.0 & 11.0 & 113.0 & 0.4 & 84.0 & 0.1 & $7.0 \pm 3.1$ & $24.6 \pm 13.7$ & Powder (P1) \\
\hline 4 & Corylus avellana (hazel) & 263.0 & 28.8 & 119.0 & 0.5 & 46.0 & 0.2 & $6.1 \pm 3.7$ & $20.4 \pm 13.7$ & Powder (P1) \\
\hline 5 & Taxus baccata (common yew) & 40.0 & 0.2 & 28.0 & 0.1 & 34.0 & 0.0 & $2.6 \pm 2.2$ & $16.0 \pm 12.2$ & Powder (P1) \\
\hline 6 & Rumex acetosella (sheep sorrel) & 417.0 & 87.1 & 88.0 & 0.4 & 71.0 & 0.1 & $6.0 \pm 2.5$ & $24.4 \pm 12.4$ & Powder (P1) \\
\hline 7 & Olea europaea (European olive tree) & 40.0 & 1.9 & 22.0 & 0.1 & 33.0 & 0.0 & $2.6 \pm 1.6$ & $10.4 \pm 9.3$ & Powder (P1) \\
\hline 8 & Alnus glutinosa (black alder) & 46.0 & 4.6 & 46.0 & 0.3 & 44.0 & 0.2 & $6.1 \pm 3.2$ & $25.2 \pm 14.6$ & Powder (P1) \\
\hline 9 & Phleum pratense (Timothy grass) & 2047.0 & 85.5 & 129.0 & 1.2 & 63.0 & 0.1 & $6.0 \pm 3.2$ & $23.1 \pm 13.4$ & Powder (P1) \\
\hline 10 & Populus alba (white poplar) & 642.0 & 35.2 & 237.0 & 8.6 & 103.0 & 0.5 & $7.4 \pm 4.0$ & $24.7 \pm 14.2$ & Powder (P1) \\
\hline 11 & Taraxacum officinale (common dandelion) & 2047.0 & 71.9 & 195.0 & 0.4 & 88.0 & 0.8 & $6.1 \pm 3.1$ & $23.7 \pm 13.5$ & Powder (P1) \\
\hline 12 & Amaranthus retroflexus (redroot amaranth) & 104.0 & 15.6 & 138.0 & 5.6 & 101.0 & 3.4 & $7.3 \pm 2.8$ & $27.7 \pm 14.6$ & Powder (P1) \\
\hline 13 & Aesculus hippocastanum (horse chestnut) & 43.0 & 6.0 & 106.0 & 0.2 & 42.0 & 0.2 & $4.3 \pm 3.1$ & $19.7 \pm 13.4$ & Powder (P1) \\
\hline \multicolumn{11}{|c|}{ Fungal spores } \\
\hline 1 & Aspergillus brasiliensis & 1279.0 & 38.5 & 22.0 & 0.0 & 33.0 & 0.0 & $3.6 \pm 1.8$ & $20.8 \pm 10.3$ & Fungal \\
\hline 2 & Aspergillus niger; WB 326 & 543.0 & 6.2 & 18.0 & 0.0 & 29.0 & 0.0 & $2.7 \pm 0.9$ & $17.1 \pm 10.7$ & Fungal \\
\hline 3 & Rhizopus stolonifer (black bread mold); UNB-1 & 78.0 & 11.2 & 20.0 & 0.1 & 34.0 & 0.1 & $4.4 \pm 2.3$ & $21.4 \pm 14.4$ & Fungal \\
\hline 4 & Saccharomyces cerevisiae (brewer's yeast) & 2047.0 & 96.6 & 97.0 & 0.3 & 41.0 & 0.1 & $7.2 \pm 3.7$ & $28.7 \pm 16.8$ & Fungal \\
\hline 5 & Aspergillus versicolor; NRRL 238 & 2047.0 & 78.2 & 55.0 & 0.0 & 40.0 & 0.0 & $4.5 \pm 2.5$ & $24.5 \pm 16.9$ & Fungal \\
\hline \multicolumn{11}{|c|}{ Bacteria } \\
\hline 1 & Bacillus atrophaeus & 443.0 & 1.0 & 10.0 & 0.0 & 36.0 & 0.0 & $2.2 \pm 0.4$ & $17.4 \pm 4.1$ & Bacterial \\
\hline 2 & Escherichia coli & 454.0 & 1.4 & 12.0 & 0.0 & 33.0 & 0.0 & $1.2 \pm 0.3$ & $19.3 \pm 2.8$ & Bacterial \\
\hline 3 & Pseudomonas stutzeri & 675.0 & 0.4 & 16.0 & 0.0 & 36.0 & 0.0 & $1.1 \pm 0.3$ & $19.2 \pm 2.8$ & Bacterial \\
\hline \multicolumn{11}{|c|}{ Biofluorophores } \\
\hline 1 & Riboflavin & 41.0 & 0.0 & 190.0 & 2.5 & 119.0 & 1.3 & $2.5 \pm 2.5$ & $13.2 \pm 12.2$ & Powder (P1) \\
\hline 2 & Chitin & 116.5 & 6.2 & 61.0 & 0.1 & 40.0 & 0.0 & $2.7 \pm 2.1$ & $16.1 \pm 13.5$ & Powder (P1) \\
\hline 3 & NAD & 49.0 & 0.2 & 962.0 & 26.7 & 515.0 & 15.0 & $2.1 \pm 2.2$ & $12.2 \pm 10.1$ & Powder (P1) \\
\hline 4 & Folic acid & 41.0 & 0.0 & 34.0 & 0.1 & 28.0 & 0.1 & $3.7 \pm 3.4$ & $18.6 \pm 13.6$ & Powder (P1) \\
\hline 5 & Cellulose, fibrous medium & 54.0 & 0.2 & 37.0 & 0.1 & 27.0 & 0.0 & $3.7 \pm 2.5$ & $20.4 \pm 15.7$ & Powder (P1) \\
\hline 6 & Ergosterol & 2047.0 & 81.8 & 457.0 & 2.6 & 355.0 & 11.6 & $6.8 \pm 4.0$ & $22.6 \pm 12.9$ & Powder (P1) \\
\hline 7 & Pyridoxine & 661.0 & 0.0 & 39.0 & 0.0 & 28.0 & 0.0 & $1.0 \pm 0.2$ & $20.0 \pm 13.0$ & Powder (P1) \\
\hline 8 & Pyridoxamine & 706.0 & 10.7 & 40.0 & 0.0 & 28.0 & 0.0 & $5.2 \pm 2.5$ & $20.2 \pm 12.7$ & Powder (P1) \\
\hline 9 & Tyrosine & 2047.0 & 59.7 & 42.0 & 0.0 & 29.0 & 0.0 & $2.9 \pm 3.4$ & $15.4 \pm 11.6$ & Powder (P1) \\
\hline 10 & Phenylalanine & 53.0 & 0.0 & 29.0 & 0.0 & 24.0 & 0.0 & $3.2 \pm 2.0$ & $21.1 \pm 15.4$ & Powder (P1) \\
\hline 11 & Tryptophan & 2047.0 & 78.0 & 357.0 & 9.0 & 30.0 & 0.0 & $3.5 \pm 2.9$ & $20.9 \pm 17.0$ & Powder (P1) \\
\hline 12 & Histidine & 59.0 & 0.2 & 29.0 & 0.0 & 25.0 & 0.0 & $2.0 \pm 1.7$ & $11.6 \pm 10.0$ & Powder (P1) \\
\hline
\end{tabular}


Table 2. Continued.

\begin{tabular}{|c|c|c|c|c|c|c|c|c|c|c|}
\hline \multicolumn{2}{|c|}{ Materials } & FL1 & $\begin{array}{r}\text { FL1 Sat } \\
\%\end{array}$ & FL2 & $\begin{array}{r}\text { FL2 Sat } \\
\%\end{array}$ & FL3 & $\begin{array}{r}\text { FL3 Sat } \\
\%\end{array}$ & $\begin{array}{l}\text { Size } \\
(\mu \mathrm{m})\end{array}$ & $\mathrm{AF}$ & $\begin{array}{l}\text { Aerosolization } \\
\text { method }\end{array}$ \\
\hline \multicolumn{11}{|c|}{ Non-biological materials } \\
\hline 1 & Arabic sand & 48.0 & 0.1 & 37.0 & 0.0 & 29.0 & 0.0 & $3.1 \pm 2.2$ & $16.1 \pm 15.7$ & Powder (P3) \\
\hline 2 & California sand & 66.0 & 1.1 & 42.0 & 0.0 & 31.0 & 0.0 & $4.0 \mathrm{v} 1.9$ & $18.8 \pm 14.6$ & Powder (P2) \\
\hline 3 & Africa sand & 88.0 & 0.0 & 48.0 & 0.0 & 26.0 & 0.0 & $2.2 \pm 1.4$ & $15.3 \pm 11.0$ & Powder (P2) \\
\hline 4 & Murkee-Murkee Australian sand & 88.0 & 0.7 & 47.0 & 0.0 & 26.0 & 0.0 & $1.9 \pm 1.1$ & $10.9 \pm 9.2$ & Powder (P2) \\
\hline 5 & Manua Key Summit Hawaiian sand & 54.0 & 0.1 & 33.0 & 0.0 & 25.0 & 0.0 & $1.5 \pm 0.7$ & $10.8 \pm 13.4$ & Powder (P2) \\
\hline 6 & Quartz & 66.0 & 0.0 & 38.0 & 0.0 & 24.0 & 0.0 & $1.7 \pm 0.8$ & $11.2 \pm 12.7$ & Powder (P2) \\
\hline 7 & Kakadu dust & 58.0 & 0.0 & 35.0 & 0.0 & 25.0 & 0.0 & $2.7 \pm 1.4$ & $15.0 \pm 12.0$ & Powder (P2) \\
\hline 8 & Feldspar & 60.0 & 0.0 & 36.0 & 0.0 & 25.0 & 0.0 & $1.2 \pm 0.6$ & $10.2 \pm 10.6$ & Powder (P2) \\
\hline 9 & Hematite & 51.0 & 0.0 & 32.0 & 0.0 & 25.0 & 0.0 & $1.8 \pm 1.0$ & $10.8 \pm 11.9$ & Powder (P2) \\
\hline 10 & Gypsum & 49.0 & 0.0 & 30.0 & 0.0 & 26.0 & 0.0 & $4.1 \pm 3.0$ & $19.3 \pm 12.2$ & Powder (P2) \\
\hline 11 & Bani AMMA & 48.0 & 0.2 & 31.0 & 0.0 & 26.0 & 0.0 & $3.1 \pm 2.1$ & $15.8 \pm 13.7$ & Powder (P2) \\
\hline 12 & Arizona test dust & 46.0 & 0.0 & 29.0 & 0.0 & 25.0 & 0.0 & $1.4 \pm 0.7$ & $10.5 \pm 10.5$ & Powder (P2) \\
\hline 13 & Kaolinite & 46.0 & 0.0 & 29.0 & 0.0 & 25.0 & 0.0 & $1.5 \pm 0.8$ & $9.9 \pm 10.3$ & Powder (P2) \\
\hline \multicolumn{11}{|c|}{ HULIS } \\
\hline 1 & Waskish peat humic acid reference & 46.0 & 0.0 & 29.0 & 0.0 & 25.0 & 0.0 & $1.7 \pm 0.8$ & $10.9 \pm 9.8$ & Powder (P1) \\
\hline 2 & Suwannee River humic acid standard II & 46.0 & 0.0 & 30.0 & 0.0 & 26.0 & 0.0 & $2.0 \pm 1.2$ & $13.2 \pm 16.5$ & Powder (P2) \\
\hline 3 & Suwannee River fulvic acid standard I & 46.0 & 0.0 & 34.0 & 0.0 & 28.0 & 0.0 & $1.7 \pm 1.0$ & $12.0 \pm 10.1$ & Powder (P2) \\
\hline 4 & Elliott soil humic acid standard & 47.0 & 0.0 & 29.0 & 0.0 & 25.0 & 0.0 & $1.2 \pm 0.6$ & $10.5 \pm 10.2$ & Powder (P1) \\
\hline 5 & Pony Lake (Antarctica) fulvic acid reference & 46.0 & 0.0 & 49.0 & 0.0 & 37.0 & 0.0 & $2.4 \pm 1.8$ & $14.0 \pm 13.3$ & Powder (P2) \\
\hline 6 & Nordic aquatic fulvic acid reference & 48.0 & 0.1 & 32.0 & 0.0 & 27.0 & 0.0 & $1.8 \pm 1.4$ & $11.6 \pm 9.6$ & Powder (P2) \\
\hline \multicolumn{11}{|c|}{ Polycyclic hydrocarbons } \\
\hline 1 & Pyrene & 490.0 & 7.4 & 2047.0 & 91.5 & 2047.0 & 81.8 & $5.0 \pm 3.5$ & $17.4 \pm 12.6$ & Powder (P1) \\
\hline 2 & Phenanthrene & 2047.0 & 81.9 & 2047.0 & 66.3 & 360.0 & 22.4 & $3.9 \pm 3.5$ & $14.5 \pm 13.6$ & Powder (P1) \\
\hline 3 & Naphthalene & 886.0 & 11.6 & 45.0 & 2.1 & 30.0 & 0.7 & $1.1 \pm 1.0$ & $10.6 \pm 9.5$ & Powder (P1) \\
\hline \multicolumn{11}{|c|}{ Combustion soot and smoke } \\
\hline 1 & Aquadag & 22.0 & 0.0 & 14.0 & 0.0 & 29.0 & 0.0 & $1.2 \pm 0.6$ & $10.5 \pm 6.6$ & Liquid \\
\hline 2 & Ash & 48.0 & 0.2 & 31.0 & 0.0 & 23.0 & 0.0 & $1.7 \pm 1.3$ & $12.6 \pm 11.9$ & Powder (P1) \\
\hline 3 & Fullerene soot & 318.0 & 0.0 & 30.0 & 0.0 & 26.0 & 0.0 & $1.1 \pm 0.5$ & $17.0 \pm 10.6$ & Powder (P2) \\
\hline 4 & Diesel soot & 750.5 & 0.2 & 30.0 & 0.0 & 26.0 & 0.0 & $1.1 \pm 0.4$ & $21.2 \pm 10.1$ & Powder (P1) \\
\hline 5 & Cigarette smoke & 28.0 & 0.6 & 30.0 & 0.1 & 36.0 & 0.0 & $1.0 \pm 0.8$ & $9.5 \pm 4.5$ & Smoke \\
\hline 6 & Wood smoke (Pinus Nigra, black pine) & 32.0 & 0.1 & 30.0 & 0.0 & 36.0 & 0.0 & $1.0 \pm 0.7$ & $9.5 \pm 4.3$ & Smoke \\
\hline 7 & Fire ash & 42.0 & 0.2 & 33.0 & 0.0 & 28.0 & 0.0 & $1.8 \pm 1.2$ & $14.0 \pm 16.7$ & Powder (P1) \\
\hline \multicolumn{11}{|c|}{ Brown carbon } \\
\hline 1 & Methylglyoxal + glycine & 17.0 & 0.0 & 53.0 & 0.0 & 88.0 & 0.0 & $1.2 \pm 0.4$ & $18.4 \pm 3.1$ & Liquid \\
\hline 2 & Glycolaldehyde + methylamine & 15.0 & 0.0 & 19.0 & 0.0 & 47.0 & 0.0 & $1.2 \pm 0.4$ & $17.9 \pm 2.4$ & Liquid \\
\hline 3 & Glyoxal + ammonium sulfate & 30.0 & 0.0 & 9.0 & 0.0 & 35.0 & 0.0 & $1.3 \pm 0.6$ & $14.1 \pm 3.5$ & Liquid \\
\hline \multicolumn{11}{|c|}{ Common household fibers } \\
\hline 1 & Laboratory wipes & 112.0 & 30.6 & 54.0 & 15.2 & 47.0 & 15.4 & $3.6 \pm 5.7$ & $16.4 \pm 14.4$ & \multirow{3}{*}{$\begin{array}{l}\text { Rubbed material } \\
\text { over inlet }\end{array}$} \\
\hline 2 & Cotton t-shirt (white) & 567.0 & 34.9 & 145.0 & 16.1 & 139.0 & 16.4 & $4.9 \pm 4.7$ & $23.5 \pm 16.2$ & \\
\hline 3 & Cotton t-shirt (black) & 56.0 & 13.5 & 22.0 & 1.7 & 34.0 & 1.5 & $2.7 \pm 4.0$ & $17.6 \pm 14.8$ & \\
\hline
\end{tabular}

and indeed should be considered as interfering particle types, as will be discussed. Three common household fiber particles (laboratory wipes and two colors of cotton t-shirts) were also interrogated by rubbing samples over the WIBS inlet because of their relevance to indoor aerosol investigation (e.g., Bhangar et al., 2014, 2016; Handorean et al., 2015). These particles (dark blue dots, Fig. 2 bottom row) show varying median intensity in FL1, suggesting that sources such as tissues, cleaning wipes, and cotton clothing could be sources of fluorescent particles within certain built environments.

Another interesting point from the observations of median fluorescence intensity is that the three viable bacteria aerosolized in this study each show moderately fluorescent characteristics in FL1 and low fluorescent character- istics in FL2 and FL3 (Fig. 2a-c). A study by Hernandez et al. (2016) also focused on analysis strategies using the WIBS and shows similar results regarding bacteria. Of the 14 bacteria samples observed in the Hernandez et al. (2016) study, 13 were categorized as predominantly A-type particles, meaning they exhibited fluorescent properties in FL1 and only a very small fraction of particles showed fluorescence above the applied threshold (FT $+3 \sigma)$ in either FL2 or FL3. The FL3 channel in the WIBS-4A has an excitation of $370 \mathrm{~nm}$ and emission band of $420-650 \mathrm{~nm}$, similar to that of the UV-APS with an excitation of $355 \mathrm{~nm}$ and emission band of 420-575 nm. Previous studies have suggested that viable microorganisms (i.e., bacteria) show fluorescence characteristics in the UV-APS due to the excitation source 
of $355 \mathrm{~nm}$ that was originally designed to excite $\mathrm{NAD}(\mathrm{P}) \mathrm{H}$ and riboflavin molecules present in actively metabolizing organisms (Agranovski et al., 2004; Hairston et al., 1997; Ho et al., 1999; Pöhlker et al., 2012). Previous studies with the UV-APS and other UV-LIF instruments using approximately similar excitation wavelengths have shown a strong sensitivity to the detection of "viable" bacteria (Hill et al., 1999; Pan et al., 1999; Hairston et al., 1997; Brosseau et al., 2000). Because the bacteria here were aerosolized and detected immediately after washing from growth media, we expect that a high fraction of the bacterial signal was a result of living vegetative bacterial cells. The results presented here and from other studies using WIBS instruments, in contrast to reports using other UV-LIF instruments, suggest that the WIBS-4A is highly sensitive to the detection of bacteria using $280 \mathrm{~nm}$ excitation (only FL1 emission), but less so using the $370 \mathrm{~nm}$ excitation (FL3 emission) (e.g., Perring et al., 2015; Hernandez et al., 2016). A study by Agranovski et al. (2003) also demonstrated that the UV-APS was limited in its ability to detect endospores (reproductive bacterial cells from sporeforming species with little or no metabolic activity and thus low NAD(P)H concentration). The lack of FL3 emission observed from bacteria in the WIBS may also suggest a weaker excitation intensity in $\mathrm{Xe} 2$ with respect to $\mathrm{Xe} 1$, manifesting in lower overall FL3 emission intensity (Könemann et al., 2017). Gain voltages applied differently to PMT2 and PMT3 could also impact differences in relative intensity observed. Lastly, it has been proposed that the rapid sequence of Xe1 and Xe2 excitation could lead to quenching of fluorescence from the first excitation flash, leading to overall reduced fluorescence in the FL3 channel (Sivaprakasam et al., 2011). These factors may similarly affect all WIBS instruments and should be kept in mind when comparing results here with other UV-LIF instrument types.

\subsection{Fluorescence type varies with particle size}

The purpose of Fig. 2 is to distill complex distributions of the five data parameters into a single value for each in order to show broad trends that differentiate biological and non-biological particles. By representing the complex data in such a simple way, however, many relationships are averaged away and lost. For example, the histogram of FL1 intensity for fungal spore Aspergillus niger (Fig. S3) shows a broad distribution with long tail at high fluorescence intensity, including ca. $\sim 6 \%$ of particles that saturate the FL1 detector (Table S2). If a given distribution were perfectly Gaussian and symmetric, the mean and standard deviation values would be sufficient to fully describe the distribution. However, given that asymmetric distributions often include detector-saturating particles, no single statistical fit characterizes data for all particle types well. Median values were chosen for Fig. 2 knowing that the resultant values can reduce the physical meaning in some cases. For example, the same Aspergillus niger particles show a broad FL1 peak at $\sim 150$ a.u. and another peak at 2047 a.u. (detector saturated), whereas the median FL1 intensity is 543 a.u., at which point there is no specific peak. In this way, the median value only broadly represents the data by weighting both the broad distribution and saturating peak. To complement the median values, however, Table 2 also shows the fraction of particles that were observed to saturate the fluorescence detector in each channel.

The representation of median values for each of the five parameters (Fig. 2) shows broad separation between particle classes, but discriminating more finely between particle types with similar properties by this analysis method can be practically challenging. Rather than investigating the intensity of fluorescence emission in each channel, however, a common method of analyzing field data is to apply binary categorization for each particle in each fluorescence channel. For example, by this process, a particle is either fluorescent in a given FL channel (above emission intensity threshold) or non-fluorescent (below threshold). In this way, many of the challenges of separation introduced above are significantly reduced, though others are introduced. Perring et al. (2015) introduced a WIBS classification strategy by organizing particles sampled by the WIBS as either non-fluorescent or into one of seven fluorescence types (e.g., Fig. 1).

Complementing the perspective from Fig. 2, stacked particle type plots (Fig. 3) show qualitative differences in fluorescence emission by representing different fluorescence types as different colors. The most important observation here is that almost all individual biological particles aerosolized (top two rows of Fig. 3) are fluorescent, meaning that they exhibit fluorescence emission intensity above the standard threshold (FT baseline $+3 \sigma$ ) in at least one fluorescence channel and are depicted with a non-gray color. Figure S4 shows the stacked particle type plots for all 69 materials analyzed in this study as a comprehensive library. In contrast to the biological particles, most particles from non-biological origin were observed not to show fluorescence emission above the threshold in any of the fluorescence channels and are thus colored gray. For example, 11 of the 15 samples of dust aerosolized show $<15 \%$ of particles to be fluorescent at particle sizes $<4 \mu \mathrm{m}$. Similarly, four of five samples of HULIS aerosolized show $<7 \%$ of particles to be fluorescent at particle sizes $<4 \mu \mathrm{m}$. The size cut point here was chosen arbitrarily to summarize the distributions. Two examples shown in Fig. 3 (Dust 10 and HULIS 3) are representative of average dust and HULIS types analyzed, respectively, and are relatively non-fluorescent. Of the four dust types that exhibit a higher fraction of fluorescence, two (Dust 3 and Dust 4) are relatively similar and show $\sim 75 \%$ fluorescent particles $<4 \mu \mathrm{m}$, with particle type divided nearly equally across the A, B, and AB types (Fig. S4i). The two others (Dust 2 and Dust 6) show very few similarities between one another, where Dust 2 shows size-dependent fluorescence and Dust 6 shows particle type A and B at all particle sizes (Fig. S4i). As seen by the median fluorescence intensity representation (Fig. 2, 

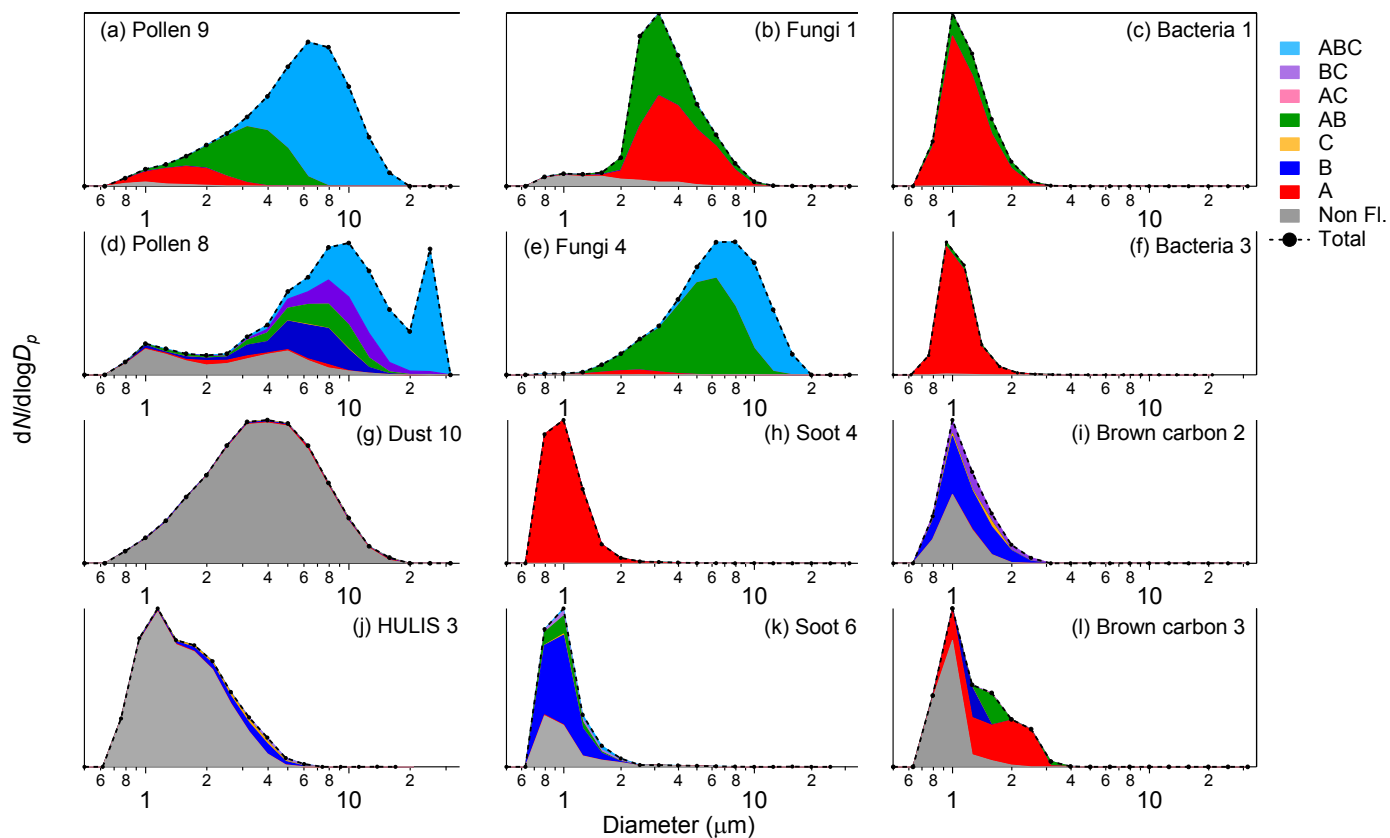

Figure 3. Stacked particle type size distributions including particle type classification, as introduced by introduced by Perring et al. (2015) using FT $+3 \sigma$ threshold definition. Examples of each material type were selected to show general trends from larger pool of samples. Soot 4 (h) is an example of combustion soot and Soot 6 (wood smoke) is an example of smoke aerosol.

Table 2), however, the relative intensity in each channel for all dusts is either below or only marginally above the fluorescence threshold. Thus, the threshold value becomes critically important and can dramatically impact the classification process, as will be discussed in a following section. Similarly, HULIS 5 (Fig. S4k) is the one HULIS type that shows an anomalously high fraction of fluorescence and is represented by $\mathrm{B}, \mathrm{C}$, and $\mathrm{BC}$ particle types, but at intensity only marginally above the threshold value and at $0 \%$ detector saturation in each channel. HULIS 5 is a fulvic acid collected from a eutrophic saline coastal pond in Antarctica (Brown et al., 2004; McKnight et al., 1994). The collection site lacks the presence of terrestrial vegetation, and therefore all dissolved organic material present originates from microbes. HULIS 5, therefore, is not expected to be representative of soil-derived HULIS present in atmospheric samples in most areas of the world. We present the properties of this material as an example of relatively highly fluorescing, non-biological aerosol types that could theoretically occur, but without comment about its relative importance or abundance.

Several types of non-biological particles, specifically brown carbon and combustion soot and smoke, exhibited higher relative fractions of fluorescent particles compared to other non-biological particles. Two of the three types of brown carbon sampled show $>50 \%$ of particles to be fluorescent at sizes $>4 \mu \mathrm{m}$ (Fig. 3i, 1), though their median fluorescence is relatively low and neither shows saturation in any of the three fluorescent channels. Out of six soot samples analyzed, four showed $>69 \%$ of particles to be flu- orescent at sizes $>4 \mu \mathrm{m}$, most of which are dominated by B particle types. Two samples of combustion soot are notably more highly fluorescent in both fraction and intensity. Soot 3 (fullerene soot) and Soot 4 (diesel soot) show FL1 intensity of 318 and 751 a.u., respectively, and are almost completely represented as A particle type. The fullerene soot is not likely a good representative of most atmospherically relevant soot types, but diesel soot is ubiquitous in anthropogenically influenced areas around the world. The fact that it exhibits high median fluorescence intensity implies that increasing the baseline threshold slightly will not appreciably reduce the fraction of particles categorized as fluorescent, and these particles will thus be counted as fluorescent in most instances. The one type of wood smoke analyzed (Soot 6) shows ca. $70 \%$ fluorescent at $>4 \mu \mathrm{m}$, mostly in the B category, with moderate to low FL2 signal, which also presents similarly as cigarette smoke. Additionally, the two smoke samples in this study (Soot 5, cigarette smoke, and Soot 6, wood smoke) share similar fluorescent particle type features with two of the brown carbon samples, $\mathrm{BrC} 1$ and $\mathrm{BrC} 2$. The smoke samples are categorized predominantly as B-type particles, whereas samples more purely comprised of soot exhibit predominantly A-type fluorescence. This distinction between smoke and soot may arise partially because the smoke particles are complex mixtures of amorphous soot with condensed organic liquids, indicating that compounds similar to the brown carbon analyzed here could heavily influence the smoke particle signal. 

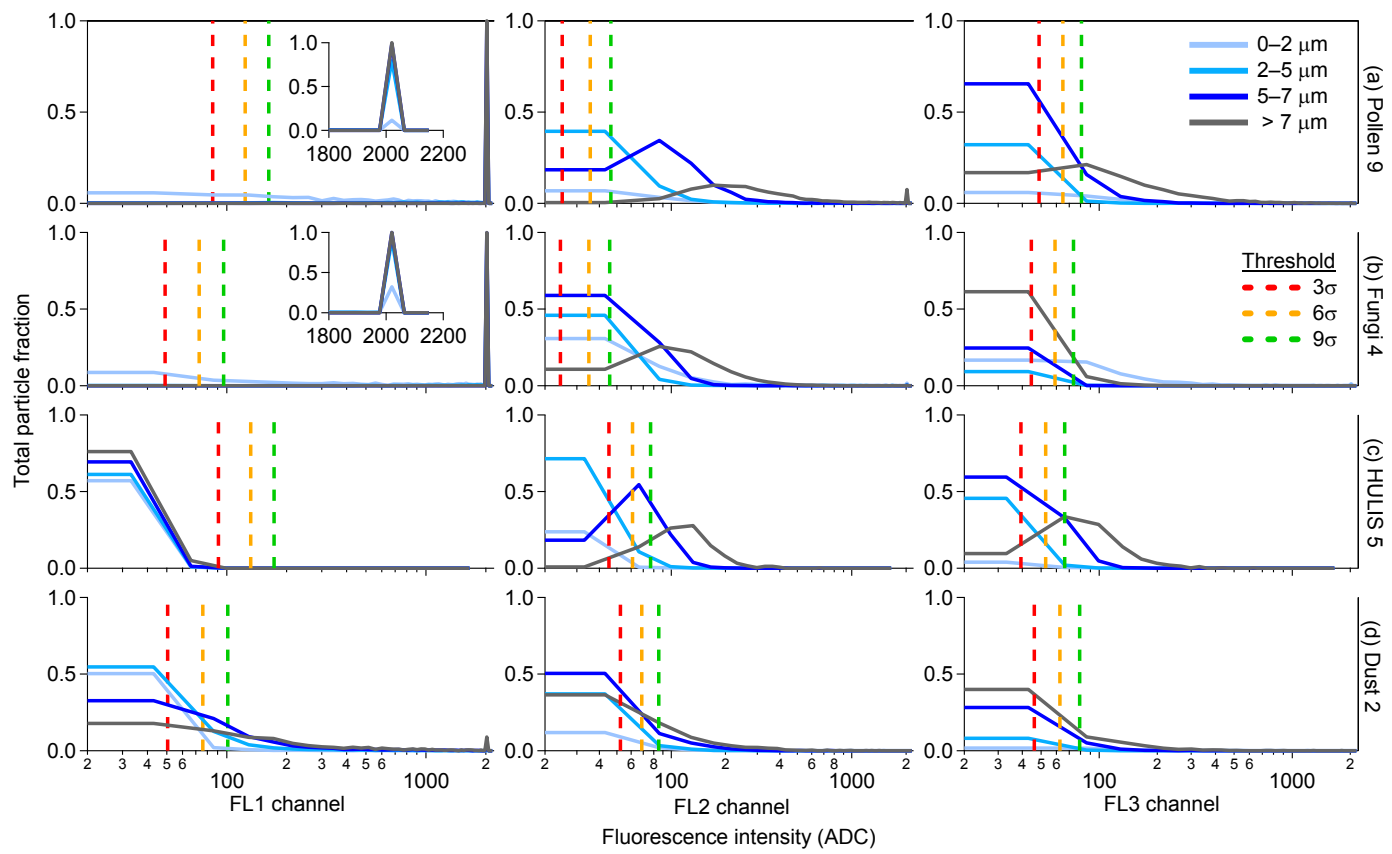

Figure 4. Relative fraction of fluorescent particles versus fluorescence intensity in analog-to-digital counts (ADC) for each channel. Particles are binned into four different size ranges (trace colors). Vertical lines indicate three thresholding definitions. Insets shown for particles that exhibit fluorescence saturation characteristics.

Biological particle samples were chosen for Fig. 3 to show the most important trends among all particle types analyzed. Two pollen are shown here to highlight two common types of fluorescence properties observed. Pollen 9 (Fig. 3a) shows particle type transitioning between $\mathrm{A}, \mathrm{AB}$, and $\mathrm{ABC}$ as particle size gets larger. Pollen 9 (Phleum pratense) has a physical diameter of $\sim 35 \mu \mathrm{m}$, so the mode seen in Fig. 3a is likely a result of fragmented pollen. Due to the upper particle size limit of WIBS detection, intact pollen of this species cannot be detected (Pöhlker et al., 2013). Pollen 8 (Fig. 3d) shows a mode peaking at $\sim 10 \mu \mathrm{m}$ in diameter and comprised of a mixture of $\mathrm{B}, \mathrm{AB}, \mathrm{BC}$, and $\mathrm{ABC}$ particles as well as a larger particle mode comprised of $\mathrm{ABC}$ particles. The large particle mode appears almost monodisperse, but this is due to the WIBS ability to sample only the tail of the distribution due to the upper size limit of particle collection $(\sim 20 \mu \mathrm{m}$ as operated). Particles larger than this limit saturate the sizing detector and are binned together into the $\sim 20 \mu \mathrm{m}$ bin. It is important to note that excitation pulses from the Xe flash lamps are not likely to penetrate the entirety of large pollen particles, and so emission information is likely limited to outer layers of each pollen grain. Excitation pulses can penetrate a relatively larger fraction of the smaller pollen fragments, however, meaning that the differences in observed fluorescence may arise from differences the layers of material interrogated. Fungi 1 (Fig. 3b) was chosen because it depicts the most commonly observed fluorescence pattern among the fungal spore types analyzed $(\sim 3 \mu \mathrm{m}$ mode mixed with $\mathrm{A}$ and $\mathrm{AB}$ particles). Fungi 4 (Fig. 3e) represents a second com- mon pattern (particle size peaking at larger diameter, minimal A-type, and dominated by $\mathrm{AB}$ and $\mathrm{ABC}$ particle types). All three bacteria types analyzed were dominated by A-type fluorescence. One gram-positive (Bacteria 1) and one gramnegative bacteria (Bacteria 3 ) types are shown in Fig. 3c and $\mathrm{f}$, respectively.

\subsection{Fluorescence intensity varies strongly with particle size}

An extension of observation from the many particle classes analyzed is that particle type $(\mathrm{A}, \mathrm{AB}, \mathrm{ABC}$, etc.) varies strongly as a function of particle size. This is not surprising, given that it has been frequently observed and reported that particle size significantly impacts fluorescence emission intensity (e.g., Hill et al., 2001; Sivaprakasam et al., 2011). The higher the fluorescent quantum yield of a given fluorophore, the more likely it is to fluoresce. For example, pure biofluorophores (middle row of Fig. 2) and PAHs (bottom row of Fig. 2) have high quantum yields and thus exhibit relatively intense fluorescence emission, even for particles $<1 \mu \mathrm{m}$. In contrast, more complex particles comprised of a wide mixture of molecular components are typically less fluorescent per volume of material. At small sizes the relative fraction of these particles that fluoresce is small, but as particles increase in size they are more likely to contain enough fluorophores to emit a sufficient number of photons to record an integrated light intensity signal above a given fluorescence threshold. Thus, the observed fluorescence intensity scales 


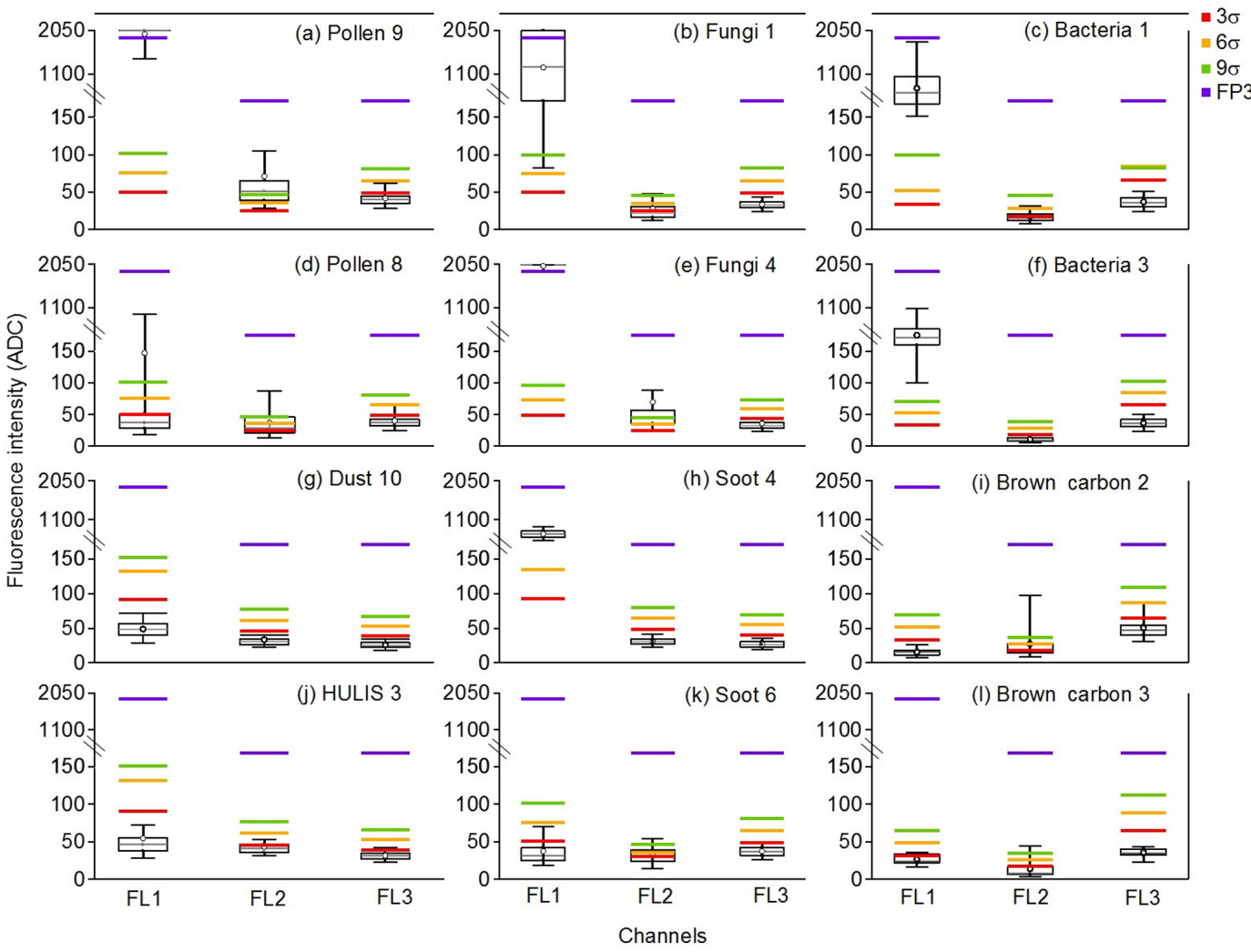

Figure 5. Box whisker plots showing statistical distributions of fluorescence intensity in analog-to-digital counts (ADC) in each channel. Averages are limited to particles in the size range 3.5-4.0 $\mu \mathrm{m}$ for pollen, fungal spore, HULIS, and dust samples and in the range 1.0-1.5 $\mu \mathrm{m}$ for bacteria, brown carbon, and soot samples. Horizontal bars associated with each box and whisker show four separate threshold levels.

approximately between the second and third power of the particle diameter (Sivaprakasam et al., 2011; Taketani et al., 2013; Hill et al., 2015).

The general trend of fluorescence dependence on size is less pronounced for FL1 than for FL2 and FL3. This can be seen by the fact that the scatter of points along the FL1 axis in Fig. $2 b$ is not clearly size dependent and is strongly influenced by particle type (i.e., composition dependent). In Fig. 2c, however, the median points cluster near the vertical (size) axis and both FL2 and FL3 values increase as particle size increases. It is important to note, however, that the method chosen for particle generation in the laboratory strongly impacts the size distribution of aerosolized particles. For example, higher concentrations of an aqueous suspension of particle material generally produce larger particles, and the mechanical force used to agitate powders or aerosolize bacteria can have strong influences on particle viability and physical agglomeration or fragmentation of the aerosol (Mainelis et al., 2005). So, while the absolute size of particles shown here is not a key message, the relative fluorescence at a given size can be informative.

As discussed, each individual particle shows increased probability of exhibiting fluorescence emission above a given fluorescence threshold as size increases. Using Pollen 9
(Phleum pratense, Fig. 3a) as an example, most particles $<3 \mu \mathrm{m}$ show fluorescence in only the FL1 channel and are thus classified as A-type particles. For the same pollen, however, particles ca. 2-6 $\mathrm{m}$ in diameter are more likely to be recorded as AB-type particles, indicating that they have retained sufficient FL1 intensity but have exceeded the FL2 threshold to add B-type fluorescence character. Particles larger still $(>4 \mu \mathrm{m})$ are increasingly likely to exhibit $\mathrm{ABC}$ character, meaning that the emission intensity in the FL3 channel has increased to cross the fluorescence threshold. Thus, for a given particle type and a constant threshold as a function of particle size, the relative breakdown of fluorescence type changes significantly as particle size increases. The same general trend can be seen in many other particle types, for example Pollen 8 (Alnus glutinosa, Fig. 3d), Fungi 1 (Aspergillus brasiliensis, Fig. 3b), and to a lesser degree HULIS 3 (Suwannee fulvic acid, Fig. 3j) and Brown Carbon 2 (Fig. 3i). The "pathway" of change, for Pollen 9, starts as A-type at small particle size and adds $\mathrm{B}$ and eventually $\mathrm{ABC}$ $(\mathrm{A} \rightarrow \mathrm{AB} \rightarrow \mathrm{ABC})$, whereas Pollen 8 starts primarily with $\mathrm{B}$ type at small particle size and separately adds either $\mathrm{A}$ or $\mathrm{C}$ en route to $\mathrm{ABC}(\mathrm{B} \rightarrow \mathrm{AB}$ or $\mathrm{BC} \rightarrow \mathrm{ABC})$. In this way, not only is the breakdown of fluorescence type useful in discrim- 

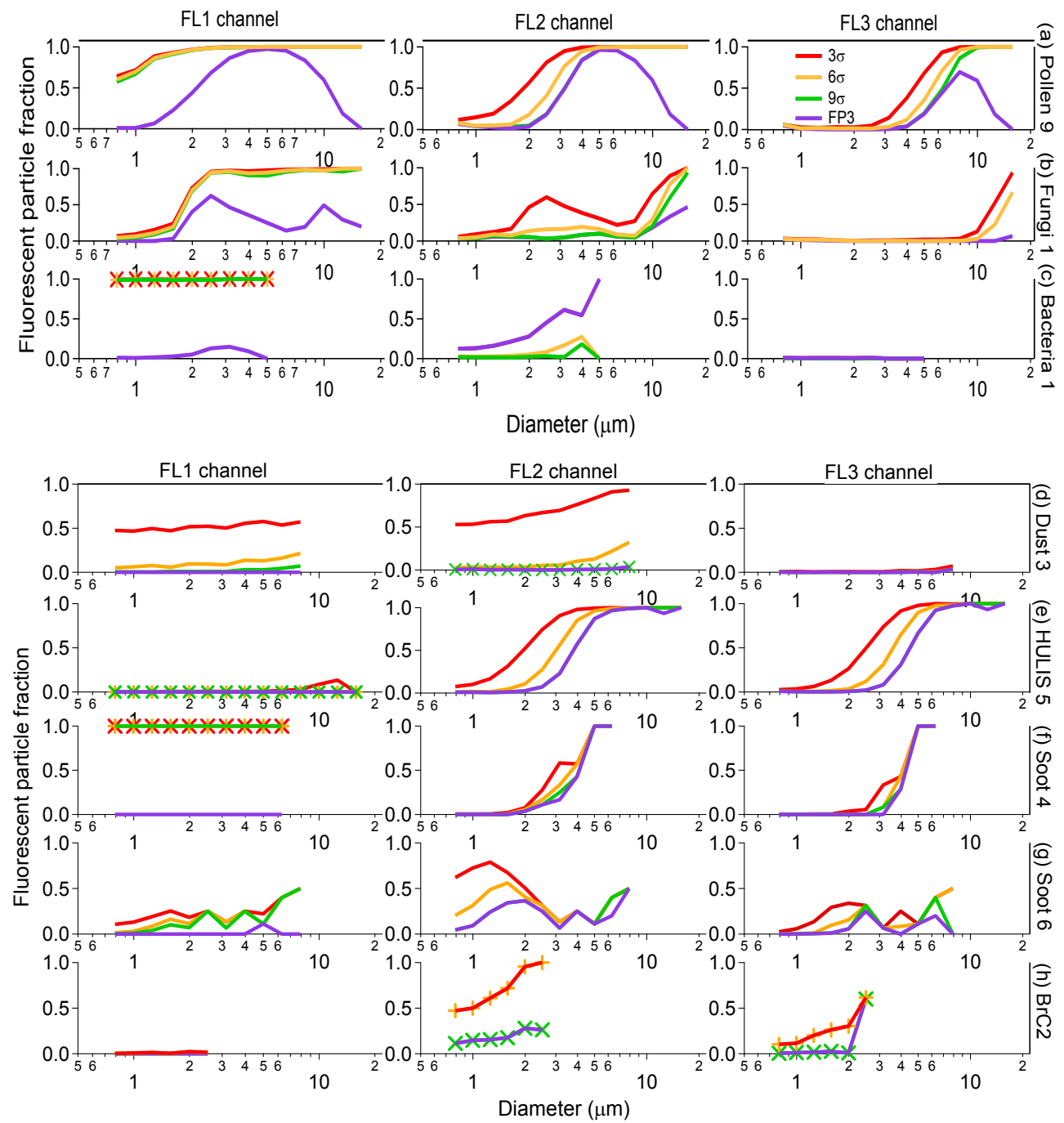

Figure 6. Fraction of particle number exhibiting fluorescent in a given channel versus particle diameter for various material types for four different thresholds definitions. Data markers shown only when disambiguation of traces is necessary. Brown carbon sample denoted by BrC.

inating particle distributions, but the pathway of fluorescence change with particle size can also be instructive.

To further highlight the relationship between particle size and fluorescence, four kinds of particles (Dust 2, HULIS 5, Fungi 4, and Pollen 9) were each binned into four different size ranges, and the relative number fraction was plotted versus fluorescence intensity signal for each channel (Fig. 4). In each case, the fluorescence intensity distribution shifts to the right (increases) as the particle size bin increases. This trend is strongest in the FL2 and FL3 (middle and right columns of Fig. 4) for most particle types, as discussed above.

The fact that particle fluorescence type can change so dramatically with increasing particle size becomes critically important when the Perring-style particle type classification is utilized for laboratory or field investigation. For example, Hernandez et al. (2016) aerosolized a variety of species of pollen, fungal spores, and bacteria in the laboratory and pre- sented the breakdown of particle types for each aerosolized species. This first comprehensive overview summarized how different types of biological material (i.e., pollen and bacteria) might be separated based on their fluorescence properties when presented with a population of relatively monodisperse particles. This was an important first step, however, because differentiation becomes more challenging when broad size distributions of particles are mixed in an unknown environment. In such a case, understanding how the particle type may change as a function of particle size may become an important aspect of analysis.

\subsection{Fluorescence threshold defines particle type}

Particle type analysis is critically affected not only by size but also by the threshold definition chosen. Figure 5 represents the same matrix of particle types as in Fig. 3 but shows the 

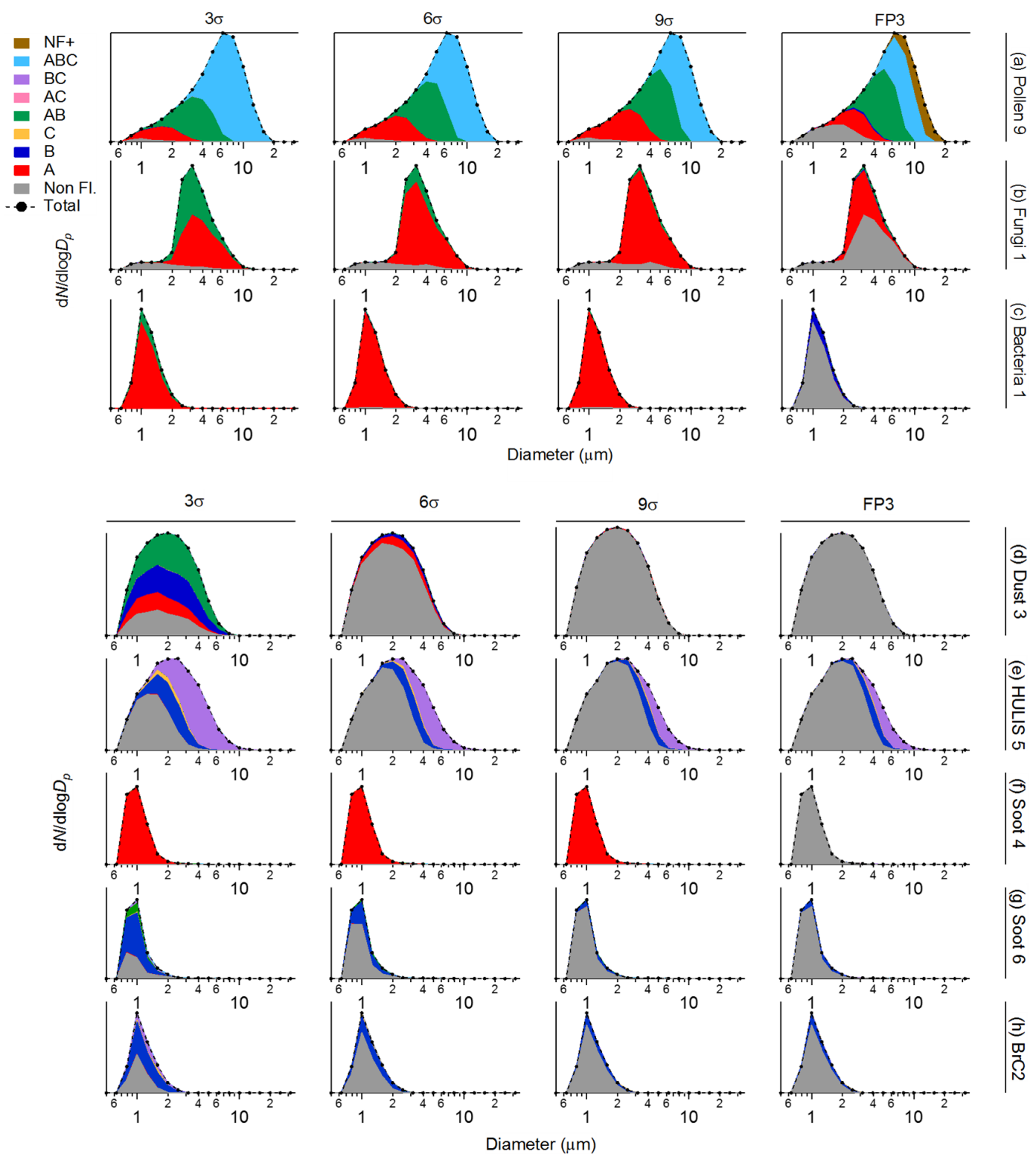

Figure 7. Stacked particle type size distributions for representative particle classes shown using four separate thresholding strategies. NF+ particle type (right-most column) represents particles that exceed the FL2 and/or FL3 upper bound of the Wright et al. (2014) FP3 definition and that are therefore considered as one set of "non-fluorescent" particles by that definition. Legend above top rows indicate threshold definition used.

fluorescence intensity distribution in each channel (at a given narrow range of sizes in order to minimize the sizing effect on fluorescence). Figure 5 can help explain the breakdown of particle type (and associated colors) shown in Fig. 3. For example, in Fig. 5a, the median fluorescence intensity in FL1 for Pollen 9 (2046 a.u., detector saturated) in the size range 3.5-4.0 $\mu \mathrm{m}$ far exceeds the $3 \sigma$ threshold (51 a.u.), and so essentially all particles exhibit FL1 character. Approximately $90 \%$ of particles of Pollen 9 are above the $3 \sigma$ FL2 threshold (25 a.u.), and approximately $63 \%$ of particles are above the $3 \sigma$ FL3 threshold (49 a.u.). These three channels of informa- tion together describe the distribution of particle type at the same range of sizes: $9 \% \mathrm{~A}, 26 \% \mathrm{AB}, 63 \% \mathrm{ABC}$, and $2 \%$ other categories. Since essentially all particles are above the threshold for FL1, particles are thus assigned as A type particles (if $<$ FL2 and FL3 thresholds), AB (if $>$ FL2 threshold and $<$ FL3 threshold), or ABC (if $>$ FL2 and FL3 thresholds). Thus, the distribution of particles at each fluorescence intensity and in relation to a given thresholding strategy defines the fluorescence type breakdown and the pathway of fluorescence change with particle size. It is important to note differences in this pathway for biofluorophores (Fig. S4g and 
h). For example, Biofluorophore 1 (riboflavin) follows the pathway $\mathrm{B}$ or $\mathrm{C} \rightarrow \mathrm{BC}$, while Biofluorophore 11 (tryptophan) follows the pathway $\mathrm{A} \rightarrow \mathrm{AB} \rightarrow \mathrm{ABC}$.

By extension, the choice of threshold bears heavily on how a given particle breakdown appears and thus how a given instrument may be used to discriminate between biological and non-biological particles. A commonly made assumption is that particles exhibiting fluorescence by the WIBS (or UVAPS) can be used as a lower limit proxy to the concentration of biological particles, though it is known that interfering particle types confound this simple assumption (Huffman et al., 2010). Increasing the fluorescence threshold can reduce categorizing weakly fluorescent particles as biological but can also remove weakly fluorescing biological particles of interest (Huffman et al., 2012). Figure 6 provides an analysis of eight representative particle types (three biological, five non-biological) in order to estimate the tradeoffs of increasing fluorescence threshold separately in each channel. Once again, the examples chosen here represent general trends and outliers, as discussed previously for Fig. 3. Four threshold strategies are presented: three as the instrument fluorescence baseline plus increasing uncertainty on that signal (FT $+3 \sigma$, $\mathrm{FT}+6 \sigma$, and FT $+9 \sigma$ ), as well as the FP3 strategy suggested by Wright et al. (2014). Using Dust 4 as an example (Fig. 6d), by increasing the threshold from $3 \sigma$ (red traces) to $6 \sigma$ (orange traces), the fraction of dust particles fluorescent in FL1 decreases from approximately 50 to $10 \%$. Increasing the fluorescence threshold even higher to $9 \sigma$ reduces the fraction of fluorescence to approximately $1 \%$, thus eliminating nearly all interfering particles of Dust 3 . In contrast, for biological particles such as Pollen 9 (Fig. 6b), increasing the threshold from $3 \sigma$ to $9 \sigma$ does very little to impact the relative breakdown of fluorescence category or the fraction of particles considered fluorescent in at least one channel. Changing threshold from $3 \sigma$ to $9 \sigma$ decreases the FL1 fraction minimally ( 98.3 to $97.9 \%$ ), and for FL2 and FL3 the fluorescence fraction decreases from 90 to $50 \%$ and from 60 to $42 \%$, respectively. Figure 6 also underscores how increasing particle size affects fluorescence fraction, as several particle types (e.g., Pollen 9 and HULIS 5) show sigmoidal curves that proceed toward the right (lower fraction at a given size) as the threshold applied increases and thus removes more weakly fluorescent particles.

To better understand how the different thresholding strategies qualitatively change the distribution of particle fluorescence type, Fig. 7 shows stacked fluorescence type distributions for each of the four thresholds analyzed. Looking first at Dust 3 (Fig. 7d), the standard threshold definition of $3 \sigma$ shows approximately $80 \%$ of particles to be fluorescent in at least one channel, resulting in a distribution of predominantly A, B, and AB-type particles. As the threshold is increased, however, the total percentage of fluorescent particles decreases dramatically to $1 \%$ at $9 \sigma$ and the particle type of the few remaining particles shifts to A-type particles. A similar trend of fluorescent fraction can also be seen for Soot 6 (wood smoke) and Brown Carbon 2, where almost no particle (10 and $16 \%$, respectively) remain fluorescent using the $9 \sigma$ threshold. Soot 4 (diesel soot), in contrast, exhibits the same fraction and breakdown of fluorescent particles whether using the $3 \sigma$ or $9 \sigma$ threshold. Using the FP3 threshold (which employs very high FL1 threshold), however, the fluorescent properties of the diesel soot change dramatically to nonfluorescent. As a "worst-case" scenario, HULIS 5 shows ca. $60 \%$ of particles to be fluorescent using the $3 \sigma$ threshold, but this material is unlikely to be representative of commonly observed soil HULIS, as discussed above. In this case, increasing the threshold from $6 \sigma$ to $9 \sigma$ only marginally decreases the fraction of fluorescent particles to ca. 35 and $22 \%$, respectively, and the breakdown remains relatively constant in $\mathrm{B}, \mathrm{C}$, and BC types. Changing the threshold definition to FP3 in this case also does not significantly change the particle type breakdown, since the high FP3 threshold applies only to FL1.

As stated, the WIBS is most often applied toward the detection and characterization of biological aerosol particles. For the biological particles analyzed (Fig. 7, top rows), increasing the threshold from $3 \sigma$ to $9 \sigma$ shows only a marginal decrease in the total fluorescent fraction for Pollen 9, Fungal Spore 1, and Bacteria 1 and only a slight shift in fluorescence type as a function of size. Using the FP3 threshold, however, for each of the three biological species the non-fluorescent fraction increases substantially. Wright et al. (2014) found that the FP3 threshold definition showed a strong correlation with ice nucleating particles and the authors suggested these particles with high FL1 intensity were likely to be fungal spores. This may have been the case, but given the analysis here, the FP3 threshold is also likely to significantly underestimate fungal spore number by missing weakly or marginally fluorescent spores.

Based on the threshold analysis results shown in Fig. 7, marginally increasing the threshold in each case may help eliminate non-biological, interfering particles without significantly impacting the number of biological particles considered fluorescent. Each threshold strategy brings tradeoffs, and individual users must understand these factors to make appropriate decisions for a given scenario. These data suggest that using a threshold definition of FT baseline $+9 \sigma$ is likely to reduce interferences from most non-biological particles without significantly impacting most biological particles.

\subsection{Particle asymmetry varies with particle size}

As a part of the comprehensive WIBS study, particle asymmetry (AF) was analyzed as a function of particle size for all particles. As described in Sect. 2.1, AF in the WIBS-4A is determined by comparing the symmetry of the forward elastic scattering response of each particle, measured at the quadrant PMT. Many factors are related to the accuracy of the asymmetry parameter, including the spatial alignment of the 


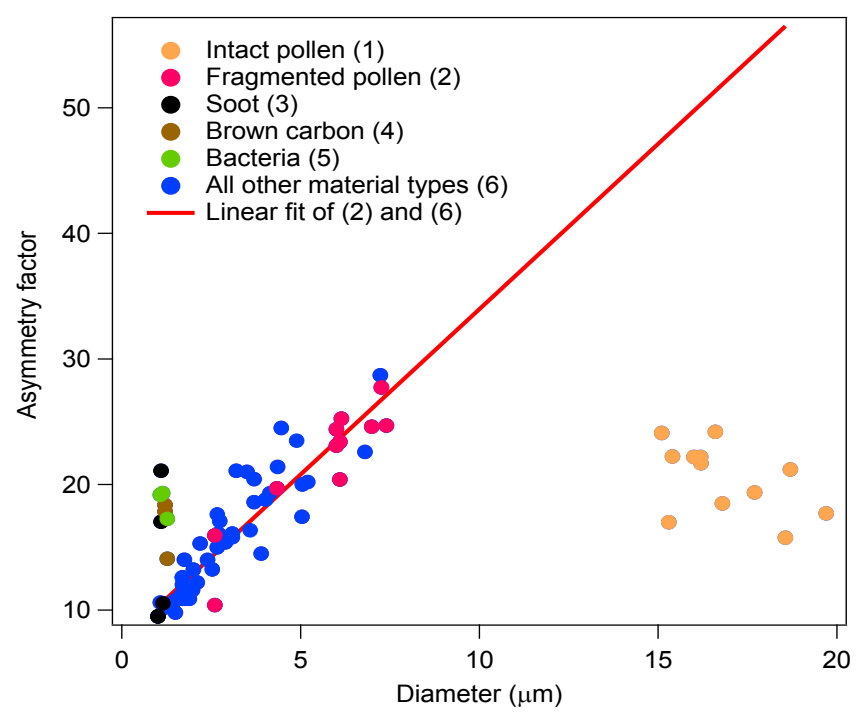

Figure 8. Median values of particle asymmetry factor versus particle size for all particle types analyzed. Fitted linear regression shown, with equation $y=2.63 x+7.64$ and $R^{2}=0.87$. Linear regression analysis was done for samples pooled from the categories of Fragmented Pollen (2) and All Other Material Types (6).

collection optics, signal-to-noise ratio and dynamic range of the detector, agglomeration of particles with different refractive indices, and the angle at which a non-symmetrical particle hits the laser (Kaye et al., 2007; Gabey et al., 2010). Figure 8 shows a summary of the relationship between AF and particle size for all material types analyzed in Table 2. Soot particles are known to frequently cluster into chains or rings depending on the number of carbon atoms (Von Helden et al., 1993) and, as a result, can have long aspect ratios that would be expected to manifest as large AF values. The bacteria species chosen have rod-like shape features and thus would also exhibit large AF values. These properties were observed by the WIBS, as two types of soot (diesel and fullerene) and all three bacteria showed higher AF values than other particles at approximately the same particle diameter. For an unknown reason, all three brown carbon samples also showed relatively high $\mathrm{AF}$ values given that the individual particles of liquid organic aerosol would be expected to be spherical with low AF. Similarly, the intact pollen showed anomalously low AF, because a substantial fraction of each was shown to saturate the WIBS sizing detector, even if the median particle size (shown) is lower than the saturating value. For this reason we postulate that the forward-scattering detector may not be able to reliably estimate AF when particles are near the sizing limits. Intact pollen, soot samples (diesel and fullerene soot), bacteria, and brown carbon samples were excluded from the linear regression fit because they appeared visually as outliers to the trend. All remaining particle groups of material types (seven in total) are represented by blue in Fig. 8. A linear regression $R^{2}$ value of 0.87 indicates a high degree of correlation between particle AF and size across the remaining particles. The strong correlation between these two factors across a wide range of particle types, mixed with the confounding anomaly of brown carbon, raises a question about the degree to which the asymmetry factor parameter from the WIBS-4A can be useful or, conversely, to what degree the uncertainty in AF is dominated by instrumental factors, including those listed above.

\section{Summary and conclusions}

UV-LIF instruments, including the WIBS, are common tools for the detection and characterization of biological aerosol particles. The number of commercially available instruments regularly deployed for ambient monitoring of environmental particle properties is rising steeply, yet critical laboratory work has been needed to better understand how the instruments categorize a variety of both biological and nonbiological particles. In particular, the differentiation between weakly fluorescent, interfering particles of non-biological origin and weakly fluorescing biological particles is very challenging. Here we have aerosolized a representative list of pollen, fungal spores, and bacteria along with key aerosol types from the groups of fluorescing non-biological materials expected to be most problematic for UV-LIF instrumentation.

By analyzing the five WIBS data parameter outputs for each interrogated particle, we have summarized trends within each class of particles and demonstrated the ability of the instrument to broadly differentiate populations of particles. The trend of particle fluorescence intensity and changing particle fluorescence type as a function of particle size was shown in detail. This is critically important for WIBS and other UV-LIF instrumentation users to keep in mind when analyzing populations of unknown ambient particles. In particular, we show that the pathway of fluorescence particle type change (e.g., $\mathrm{A} \rightarrow \mathrm{AB} \rightarrow \mathrm{ABC}$ or $\mathrm{B} \rightarrow \mathrm{BC} \rightarrow \mathrm{ABC}$ ) with increasing particle size can be one characteristic feature of unique populations of particles. When comparing the fluorescence breakdown of individual aerosol material types, care should be taken to limit comparison within a narrow range of particle sizes in order to reduce complexity due to differing composition or fluorescence intensity effects. Lastly, we looked at the reliability of using the forward scattering to estimate particle shape. Results showed a strong correlation between AF and size for various biological and non-biological particles, indicating the AF parameter may not be reliable for discriminating between different particle types.

The fluorescence threshold applied toward binary categorization of fluorescence or non-fluorescent in each channel is absolutely critical to the conceptual strategy that a given user applies to ambient particle analysis. A standard WIBS threshold definition of instrument background (FT baseline) $+3 \sigma$ is commonly applied to discriminate between particles with or without fluorescence. As has been shown 
previously, however, any single threshold confounds simple discrimination of biological and non-biological particles by mixing poorly fluorescent biological material into nonfluorescent categories and highly fluorescent non-biological material into fluorescent categories. Previously introduced thresholding strategies were also used for comparison. The Wright et al. (2014) definition was shown to aid in removing non-biological particles such as soot but also to lead to the dramatic underestimation of the biological fraction. The strategy utilized by Toprak and Schnaiter (2013) was to define fluorescent biological particles as those with fluorescent characteristics in FL1 and FL3, ignoring any particles with fluorescence in FL2. They proposed this because FL1 shows excitation and emission characteristics well suited for the detection of tryptophan, and FL3 for the detection of NAD(P)H and riboflavin. However, the study here, along with studies by Hernandez et al. (2016) and Perring et al. (2015), has shown that FL2 fluorescence characteristics $(\mathrm{B}, \mathrm{AB}, \mathrm{BC}$, and $\mathrm{ABC}$ type) are common for many types of biological particles and so removing particles with FL2 fluorescence is likely to remove many bioparticles from characterization.

Any one threshold has associated tradeoffs and is likely to create some fraction of both false positive and false negative signals. Here we have shown a systematic analysis of four different fluorescence thresholding strategies, concluding that by raising the threshold to FT $+9 \sigma$ the reduction in biological material counted as fluorescent is likely to be only minimally effected, while the fraction of interfering material is likely to be reduced almost to zero for most particle types. Several materials exhibiting outlier behavior (e.g., HULIS 5, diesel soot) could present as false positive counts using almost any characterization scheme. It is important to note that HULIS 5 was one of a large number of analyzed particle types and in the minority of HULIS types, however, and it is unlikely that this microbe-derived material would be observed in a given ambient air mass at most locations. More studies may be required to sample dusts, HULIS types, soot and smoke, brown organic carbon materials, and various coatings in different real-world settings and at various stages of aging to better understand how specific aerosol types may contribute to UV-LIF interpretation at a given study location. We also included a comprehensive supplemental document including size distributions for all 69 aerosol materials, stacked by fluorescent particle type and comparing the $\mathrm{FT}+3 \sigma$ and $\mathrm{FT}+9 \sigma$ threshold strategies. These figures are included as a qualitative reference for other instrument users when comparing against laboratory-generated particles or for use in ambient particle interpretation.

It is important here to provide brief atmospheric context to these measurements. Whether $3 \sigma$ or $9 \sigma$ thresholds are used, no UV-LIF technology can unambiguously distinguish between all biological and non-biological aerosol types, and so a minority of misidentified particles will always remain. The key aim is not to remove these completely but to group particles of interest as cleanly as possible with an estimate of the relative magnitude of misidentification. As a simple exercise to estimate this process, consider two scenarios where each sampled air mass contains a total of 10000 particles, each $3 \mu \mathrm{m}$ in diameter.

- Assume as Scenario 1 that the particle mode is comprised of $10 \%$ Dust 10 (taken as a representative, weakly fluorescent dust), $5 \%$ Fungi 1 (taken as a representative fungal spore type), and $85 \%$ other non-fluorescent material (i.e., sea salt, silicates, nonabsorbing organic aerosol). In this scenario, $6.9 \%$ of the 485 particles exhibiting some type of fluorescence (FL_any) using the $3 \sigma$ threshold would be misidentified from fluorescing dust and separately $4.4 \%$ of the 427 particles using the $9 \sigma$ threshold.

- Assume as Scenario 2 that a strong dust event is comprised of $90 \%$ Dust 10 mixed $10 \%$ Fungi 1 . Here, $25 \%$ of the 1139 fluorescent particles would be misidentified from dust using the $3 \sigma$ threshold and $17.2 \%$ of 985 fluorescent particles using $9 \sigma$.

These simple calculations using only dust and fungal spores suggest that a minimum of a few percent of fluorescing particles are expected to arise from non-biological materials, and so the uncertainty in the fraction of fluorescence by these types of analyses is probably limited to no lower than $\pm 5 \%$. The uncertainty in assigning the absolute number of fluorescent particles to biological material is somewhat more uncertain, however. For example, if 10000 dust particles of which only $1 \%$ were fluorescent were to be mixed with a small population of 100 biological particles of which $100 \%$ were fluorescent, then the number concentration of fluorescent particles would overcount the biological particles by a factor of 2. In this way, the number concentration of fluorescent particles is much more susceptible to uncertainties from nonbiological particles. The overall uncertainty in discerning between particles will also be strongly dependent on air mass composition. For example, Scenario 2 hypothesized to simulate a dust storm, the fraction of particle misidentification can be significantly higher when the relative fraction of a weakly fluorescing material is especially high. Air masses that contain non-biological materials that have anomalously high fluorescent fractions would increase the rate of particle misidentification even more dramatically. These scenarios only consider the total fraction of particles to be fluorescent, not taking into account the differing breakdown of fluorescent particle type as a function of the three different fluorescent channels. Taking these details into account will reduce the fraction of particle misidentification as a function of the similarity between observed biological and non-biological material. As a result, UV-LIF results should be considered uniquely in all situations with appreciation of possible influences from differing aerosol composition on fluorescence results. Additionally, individuals utilizing WIBS instrumentation are cautioned to use the assignment of "biological aerosols" from 
UV-LIF measurements with great care and are rather encouraged to use "fluorescent aerosol" or some variation more liberally. Ultimately, further analysis methods, including clustering techniques (e.g., Crawford et al., 2015, 2016; Ruske et al., 2017), will likely need to employed to further improve discrimination between ambient particles and to reduce the relative rate of misidentification. It should also be noted, however, that a number of ambient studies have compared results of UV-LIF instruments with complementary techniques for bioaerosol detection and have reported favorable comparisons (Healy et al., 2014; Gosselin et al., 2016; Huffman et al., 2012). So while uncertainties remain, increasing anecdotal evidence supports the careful use of UV-LIF technology for bioaerosol detection.

The presented assessment is not intended to be exhaustive but has the potential to guide users of commercial UV-LIF instrumentation through a variety of analysis strategies toward the goal of better detecting and characterizing biological particles. One important point is that the information presented here is strongly instrument dependent due to fluorescence PMT voltages and gains, specific fluorescence calibrations applied, and other instrument parameters (Robinson et al., 2017). For example, the suggested particle type classification introduced by Perring et al. (2015) will vary somewhat between instruments, though more work will be necessary to determine the magnitude of these changes. Thus, we do not introduce these data primarily as a library to which all other WIBS instrument should be compared rigorously, but rather as general trends that are expected to hold broadly true.

Several examples of strongly fluorescing particles of specific importance to the built environment (e.g., cellulose fibers, particles from cotton t-shirts, laboratory wipes) show that these particle types could be very important sources of fluorescent particles indoors (i.e., Fig. S4s and t). This will also require further study, but it should be taken seriously by researchers who utilize UV-LIF instrumentation to estimate concentrations and properties of biological material within homes, indoor occupational environments, or hospitals.

The study presented here is meant broadly to achieve two aims. The first aim is to present a summary of fluorescent properties of the most important particle types expected in a given sample and to suggest thresholding strategies (i.e., FT $+9 \sigma)$ that may be widely useful for improving analysis quality. The second aim is to suggest key analysis and plotting strategies that other UV-LIF, especially WIBS, instrumentation users can utilize to interrogate particles using their own instruments. By proposing several analysis strategies we aim to introduce concepts to the broader atmospheric community in order to promote deeper discussions about how best to continue improving UV-LIF instrumentation and analyses.

Data availability. Plots in electronic format and single particle experimental data will be provided upon request.

\section{The Supplement related to this article is available online at https://doi.org/10.5194/amt-10-4279-2017-supplement.}

Competing interests. The authors declare that they have no conflict of interest.

Acknowledgements. The authors acknowledge the University of Denver for financial support from the faculty start-up fund. Nicole Savage acknowledges financial support from the Phillipson Graduate Fellowship at the University of Denver. Christine Krentz acknowledges financial support from the Summer Undergraduate Research Grant program through the Undergraduate Research Center at the University of Denver. Tobias Könemann and Christopher Pöhlker acknowledge financial support by the Max Planck Society and the Max Planck Graduate Center with the Johannes Gutenberg University Mainz (MPGC). Gediminas Mainelis acknowledges support by the New Jersey Agricultural Experiment Station (NJAES) at Rutgers, The State University of New Jersey. Ulrich Pöschl and Meinrat O. Andreae are acknowledged for useful discussions and support of the authors. Gavin McMeeking from Handix Scientific is acknowledged for the development of the WIBS analysis toolkit. Martin Gallagher, Jonathan Crosier, and the Department of Geology and Earth Science in the School of Earth and Environmental Sciences, University of Manchester, provided several samples of raw materials. The authors acknowledge Marie Gosselin for discussion about WIBS analysis, Ben Swanson for help with conceptual design of figures, and Jixiao (Yuri) Li for initial construction of fungal chamber.

Edited by: Francis Pope

Reviewed by: Anne Perring and one anonymous referee

\section{References}

Abdel-Shafy, H. I. and Mansour, M. S. M.: A review on polycyclic aromatic hydrocarbons: Source, environmental impact, effect on human health and remediation, Egyptian Journal of Petroleum, 25, 107-123, https://doi.org/10.1016/j.ejpe.2015.03.011, 2016.

Agranovski, V., Ristovski, Z., Hargreaves, M., Blackall, P. J., and Morawska, L.: Real-time measurement of bacterial aerosols with the UVAPS: performance evaluation, J. Aerosol Sci., 34, 301317, https://doi.org/10.1016/s0021-8502(02)00181-7, 2003.

Agranovski, V., Ristovski, Z. D., Ayoko, G. A., and Morawska, L.: Performance evaluation of the UVAPS in measuring biological aerosols: Fluorescence spectra from NAD(P)H coenzymes and riboflavin, Aerosol Sci. Tech., 38, 354-364, https://doi.org/10.1080/02786820490437505, 2004.

Agranovski, V., and Ristovski, Z. D.: Real-time monitoring of viable bioaerosols: capability of the UVAPS to predict the amount of individual microorganisms in aerosol particles, J. Aerosol Sci., 36, 665-676, https://doi.org/10.1016/j.jaerosci.2004.12.005, 2005.

Aizawa, T. and Kosaka, H.: Investigation of early soot formation process in a diesel spray flame via excitation-emission matrix 
using a multi-wavelength laser source, Int. J. Engine Res., 9, 7996, https://doi.org/10.1243/14680874jer01407, 2008.

Aizawa, T. and Kosaka, H.: Effects of Fischer-Tropsch diesel fuel on soot formation processes in a diesel spray flame, Int. J. Engine Res., 11, 79-87, https://doi.org/10.1243/14680874jer04709, 2010.

Amann, R. I., Ludwig, W., and Schleifer, K. H.: Phylogenetic identification and in-situ detection of individual microbial-cells without cultivation, Microbiol. Rev., 59, 143-169, 1995.

Ariya, P. A., Sun, J., Eltouny, N. A., Hudson, E. D., and Hayes, C. T.: Physical and chemical characterization of bioaerosols implications for nucleation processes, Int. Rev. Phys. Chem., 28, 1-32, 2009.

Bhangar, S., Huffman, J. A., and Nazaroff, W. W.: Size-resolved fluorescent biological aerosol particle concentrations and occupant emissions in a university classroom, Indoor Air, 24, 604617, https://doi.org/10.1111/ina.12111, 2014.

Bhangar, S., Adams, R. I., Pasut, W., Huffman, J. A., Arens, E. A., Taylor, J. W., Bruns, T. D., and Nazaroff, W. W.: Chamber bioaerosol study: human emissions of size-resolved fluorescent biological aerosol particles, Indoor Air, 26, 193-206, https://doi.org/10.1111/ina.12195, 2016.

Bones, D. L., Henricksen, D. K., Mang, S. A., Gonsior, M., Bateman, A. P., Nguyen, T. B., Cooper, W. J., and Nizkorodov, S. A.: Appearance of strong absorbers and fluorophores in limoneneO3 secondary organic aerosol due to $\mathrm{NH}_{4-}^{+}$mediated chemical aging over long time scales, J. Geophys. Res., 115, D05203, https://doi.org/10.1029/2009JD012864, 2010.

Brosseau, L. M., Vesley, D., Rice, N., Goodell, K., Nellis, M., and Hairston, P.: Differences in detected fluorescence among several bacterial species measured with a direct-reading particle sizer and fluorescence detector, Aerosol Sci. Tech., 32, 545-558, 2000.

Brown, A., McKnight, D., Chin, Y.-P., Roberts, E., and Uhle, M.: Chemical characterization of dissolved organic material in Pony Lake, a saline coastal pond in Antarctica, Mar. Chem., 89, 327-337, https://doi.org/10.1016/j.marchem.2004.02.016, 2004.

Chi, M. C. and Li, C. S.: Fluorochrome in monitoring atmospheric bioaerosols and correlations with meteoro ogical factors and air pollutants, Aerosol Sci. Tech., 41, 672-678, 2007.

Cox, C. S. and Wathes, C. M.: Bioaerosols Handbook, Book, Whole, CRC Press, 1995.

Crawford, I., Ruske, S., Topping, D. O., and Gallagher, M. W.: Evaluation of hierarchical agglomerative cluster analysis methods for discrimination of primary biological aerosol, Atmos. Meas. Tech., 8, 4979-4991, https://doi.org/10.5194/amt-8-4979-2015, 2015.

Crawford, I., Lloyd, G., Herrmann, E., Hoyle, C. R., Bower, K. N., Connolly, P. J., Flynn, M. J., Kaye, P. H., Choularton, T. W., and Gallagher, M. W.: Observations of fluorescent aerosolcloud interactions in the free troposphere at the High-Altitude Research Station Jungfraujoch, Atmos. Chem. Phys., 16, 2273 2284, https://doi.org/10.5194/acp-16-2273-2016, 2016.

DeCarlo, P. F., Slowik, J. G., Worsnop, D. R., Davidovits, P., and Jimenez, J. L.: Particle morphology and density characterization by combined mobility and aerodynamic diameter measurements. Part 1: Theory, Aerosol Sci. Tech., 38, 1185-1205, https://doi.org/10.1080/027868290903907, 2004.
Delort, A. M., Vaitilingom, M., Amato, P., Sancelme, M., and Parazols, M.: A short overview of the microbial population in clouds: potential roles in atmospheric chemistry and nucleation processes, Atmos. Res., 98, 249-260, 2010.

Després, V. R., Huffman, J. A., Burrows, S. M., Hoose, C., Safatov, A. S., Buryak, G., Froehlich-Nowoisky, J., Elbert, W., Andreae, M. O., Pöschl, U., and Jaenicke, R.: Primary biological aerosol particles in the atmosphere: a review, Tellus Ser. B, 64, 1-58, 15598, https://doi.org/10.3402/tellusb.v64i0.15598, 2012.

Douwes, J., Thorne, P., Pearce, N., and Heederik, D.: Bioaerosol health effects and exposure assessment: Progress and prospects, Ann. Occup. Hyg., 47, 187-200, https://doi.org/10.1093/annhyg/meg032, 2003.

Finlayson-Pitts, B. J., Pitts, J., and James N.: Chemistry of the Upper and Lower Atmosphere: Theory, Experiments, and Applications, Academic Pres, San Diego, USA, 993 pp., November 1999.

Fröhlich-Nowoisky, J., Kampf, C. J., Weber, B., Huffman, J. A., Poehlker, C., Andreae, M. O., Lang-Yona, N., Burrows, S. M., Gunthe, S. S., Elbert, W., Su, H., Hoor, P., Thines, E., Hoffmann, T., Despres, V. R., and Pöschl, U.: Bioaerosols in the Earth system: Climate, health, and ecosystem interactions, Atmos. Res., 182, 346-376, https://doi.org/10.1016/j.atmosres.2016.07.018, 2016.

Gabey, A. M., Gallagher, M. W., Whitehead, J., Dorsey, J. R., Kaye, P. H., and Stanley, W. R.: Measurements and comparison of primary biological aerosol above and below a tropical forest canopy using a dual channel fluorescence spectrometer, Atmos. Chem. Phys., 10, 4453-4466, https://doi.org/10.5194/acp10-4453-2010, 2010.

Gabey, A. M., Vaitilingom, M., Freney, E., Boulon, J., Sellegri, K., Gallagher, M. W., Crawford, I. P., Robinson, N. H., Stanley, W. R., and Kaye, P. H.: Observations of fluorescent and biological aerosol at a high-altitude site in central France, Atmos. Chem. Phys., 13, 7415-7428, https://doi.org/10.5194/acp13-7415-2013, 2013.

Gosselin, M. I., Rathnayake, C. M., Crawford, I., Pöhlker, C., Fröhlich-Nowoisky, J., Schmer, B., Després, V. R., Engling, G., Gallagher, M., Stone, E., Pöschl, U., and Huffman, J. A.: Fluorescent bioaerosol particle, molecular tracer, and fungal spore concentrations during dry and rainy periods in a semi-arid forest, Atmos. Chem. Phys., 16, 15165-15184, https://doi.org/10.5194/acp-16-15165-2016, 2016.

Griffiths, W. D. and Decosemo, G. A. L.: The assessment of bioaerosols - a critical-review, J. Aerosol Sci., 25, 1425-1458, https://doi.org/10.1016/0021-8502(94)90218-6, 1994.

Hairston, P. P., Ho, J., and Quant, F. R.: Design of an instrument for real-time detection of bioaerosols using simultaneous measurement of particle aerodynamic size and intrinsic fluorescence, J. Aerosol Sci., 28, 471-482, 1997.

Hallar, A. G., Chirokova, G., McCubbin, I., Painter, T. H., Wiedinmyer, C., and Dodson, C.: Atmospheric bioaerosols transported via dust storms in the western United States, Geophys. Res. Lett., 38, L17801-L17801, https://doi.org/10.1029/2011GL048166, 2011.

Han, T., Zhen, H. J., Fennell, D. E., and Mainelis, G.: Design and Evaluation of the Field-Deployable Electrostatic Precipitator with Superhydrophobic Surface (FDEPSS) with High 
Concentration Rate, Aerosol Air Qual. Res., 15, 2397-2408, https://doi.org/10.4209/aaqr.2015.04.0206, 2015.

Handorean, A., Robertson, C. E., Harris, J. K., Frank, D., Hull, N., Kotter, C., Stevens, M. J., Baumgardner, D., Pace, N. R., and Hernandez, M.: Microbial aerosol liberation from soiled textiles isolated during routine residuals handling in a modern health care setting, Microbiome, 3, p. 72, https://doi.org/10.1186/s40168015-0132-3, 2015.

Healy, D. A., O'Connor, D. J., Burke, A. M., and Sodeau, J. R.: A laboratory assessment of the Waveband Integrated Bioaerosol Sensor (WIBS-4) using individual samples of pollen and fungal spore material, Atmos. Environ., 60, 534-543, https://doi.org/10.1016/j.atmosenv.2012.06.052, 2012.

Healy, D. A., Huffman, J. A., O'Connor, D. J., Pöhlker, C., Pöschl, U., and Sodeau, J. R.: Ambient measurements of biological aerosol particles near Killarney, Ireland: a comparison between real-time fluorescence and microscopy techniques, Atmos. Chem. Phys., 14, 8055-8069, https://doi.org/10.5194/acp14-8055-2014, 2014.

Heidelberg, J. F., Shahamat, M., Levin, M., Rahman, I., Stelma, G., Grim, C., and Colwell, R. R.: Effect of aerosolization on culturability and viability of gram-negative bacteria, Appl. Environ., 63, 3585-3588, 1997.

Hernandez, M., Perring, A. E., McCabe, K., Kok, G., Granger, G., and Baumgardner, D.: Chamber catalogues of optical and fluorescent signatures distinguish bioaerosol classes, Atmos. Meas. Tech., 9, 3283-3292, https://doi.org/10.5194/amt-9-3283-2016, 2016

Hill, S. C., Pinnick, R. G., Niles, S., Pan, Y. L., Holler, S., Chang, R. K., Bottiger, J., Chen, B. T., Orr, C. S., and Feather, G.: Real-time measurement of fluorescence spectra from single airborne biological particles, Field Anal. Chem. Technol., 3, 221-239, 1999.

Hill, S. C., Pinnick, R. G., Niles, S., Fell, N. F., Pan, Y. L., Bottiger, J., Bronk, B. V., Holler, S., and Chang, R. K.: Fluorescence from Airborne Microparticles: Dependence on Size, Concentration of Fluorophores, and Illumination Intensity, Appl. Optics, 40, 3005-3013, 2001.

Hill, S. C., Williamson, C. C., Doughty, D. C., Pan, Y. L., Santarpia, J. L., and Hill, H. H.: Size-dependent fluorescence of bioaerosols: Mathematical model using fluorescing and absorbing molecules in bacteria, J. Quant. Spectrosc. Ra., 157, 54-70, https://doi.org/10.1016/j.jqsrt.2015.01.011, 2015.

Ho, J.: Future of biological aerosol detection, Advances in Biodetection, 457, 125-148, https://doi.org/10.1016/S00032670(01)01592-6, 2002.

Ho, J., Spence, M., and Hairston, P.: Measurement of Biological Aerosol with a Fluorescent Aerodynamic Particle Sizer (FLAPS): Correlation of Optical Data with Biological Data, Aerobiologia, 15, 281, https://doi.org/10.1023/A:1007647522397, 1999.

Huffman, J. A. and Santarpia, J. L.: Online techniques for quantification and characterization of biological aerosol, in: Microbiology of Aerosols, edited by: Delort, A. M. and Amato, P., Wiley, Hoboken, NJ, chap. 1.4, 2017.

Huffman, J. A., Treutlein, B., and Pöschl, U.: Fluorescent biological aerosol particle concentrations and size distributions measured with an Ultraviolet Aerodynamic Particle Sizer (UVAPS) in Central Europe, Atmos. Chem. Phys., 10, 3215-3233, https://doi.org/10.5194/acp-10-3215-2010, 2010.
Huffman, J. A., Sinha, B., Garland, R. M., Snee-Pollmann, A., Gunthe, S. S., Artaxo, P., Martin, S. T., Andreae, M. O., and Pöschl, U.: Size distributions and temporal variations of biological aerosol particles in the Amazon rainforest characterized by microscopy and real-time UV-APS fluorescence techniques during AMAZE-08, Atmos. Chem. Phys., 12, 11997-12019, https://doi.org/10.5194/acp-12-11997-2012, 2012.

Huffman, J. A., Prenni, A. J., DeMott, P. J., Pöhlker, C., Mason, R. H., Robinson, N. H., Fröhlich-Nowoisky, J., Tobo, Y., Després, V. R., Garcia, E., Gochis, D. J., Harris, E., M"ullerGermann, I., Ruzene, C., Schmer, B., Sinha, B., Day, D. A., Andreae, M. O., Jimenez, J. L., Gallagher, M., Kreidenweis, S. M., Bertram, A. K., and Pöschl, U.: High concentrations of biological aerosol particles and ice nuclei during and after rain, Atmos. Chem. Phys., 13, 6151-6164, https://doi.org/10.5194/acp13-6151-2013, 2013.

Jaenicke, R.: Abundance of cellular material and proteins in the atmosphere, Science, 308, p. 73, 2005.

Kanaani, H., Hargreaves, M., Ristovski, Z., and Morawska, L.: Performance assessment of UVAPS: Influence of fungal spore age and air exposure, J. Aerosol Sci., 38, 83-96, https://doi.org/10.1016/j.jaerosci.2006.10.003, 2007.

Kanaani, H., Hargreaves, M., Smith, J., Ristovski, Z., Agranovski, V., and Morawska, L.: Performance of UVAPS with respect to detection of airborne fungi, J. Aerosol Sci., 39, 175-189, https://doi.org/10.1016/j.jaerosci.2007.10.007, 2008.

Kanaani, H., Hargreaves, M., Ristovski, Z., and Morawska, L.: Fungal spore fragmentation as a function of airflow rates and fungal generation methods, Atmos. Environ., 43, 3725-3735, https://doi.org/10.1016/j.atmosenv.2009.04.043, 2009.

Kaye, P. H., Aptowicz, K., Chang, R. K., Foot, V. E., and Videen, G.: Angularly resolved elastic scattering from airborne particles, Optics of Biological Particles, edited by: Hoekstra, A., Maltsev, V., and Videen, G., Springer, New York, USA, 31-61, 2007.

Kaye, P. H., Eyles, N. A., Ludlow, I. K., and Clark, J. M.: An instrument for the classification of airborne particles on the basis of size, shape, and count frequency, Atmos. Environ., 25, 645-654, https://doi.org/10.1016/0960-1686(91)90062-c, 1991.

Kaye, P. H., Stanley, W. R., Hirst, E., Foot, E. V., Baxter, K. L., and Barrington, S. J.: Single particle multichannel bioaerosol fluorescence sensor, Opt. Express, 13, 3583-3593, https://doi.org/10.1364/opex.13.003583, 2005.

Könemann, T., Savage, N., McMeeking, G., Su, H., Huffman, J. A., Pöhlker, C., and Pöschl, U.: Spectral Intensity Bioaerosol Sensor (SIBS): Technical Description and Laboratory Assessment of a Novel Instrument for Single Particle Detection, in preparation, 2017.

Lavoie, J., Marchand, G. E., Cloutier, Y., Halle, S., Nadeau, S., Duchaine, C., and Pichette, G.: Evaluation of bioaerosol exposures during hospital bronchoscopy examinations, Environ. Sci Proc., 17, 288-299, https://doi.org/10.1039/c4em00359d, 2015.

Lee, H. J., Laskin, A., Laskin, J., and Nizkorodov, S. A.: ExcitationEmission Spectra and Fluorescence Quantum Yields for Fresh and Aged Biogenic Secondary Organic Aerosols, Environ. Sci. Technol., 47, 5763-5770, 2013.

Li, J., Zhou, L., Zhang, X., Xu, C., Dong, L., and Yao, M.: Bioaerosol emissions and detection of airborne antibiotic resistance genes from a wastewater treatment plant, Atmos. Environ., 
124, 404-412, https://doi.org/10.1016/j.atmosenv.2015.06.030, 2016.

Lv, Y., Li, X., Xu, T. T., Cheng, T. T., Yang, X., Chen, J. M., Iinuma, Y., and Herrmann, H.: Size distributions of polycyclic aromatic hydrocarbons in urban atmosphere: sorption mechanism and source contributions to respiratory deposition, Atmos. Chem. Phys., 16, 2971-2983, https://doi.org/10.5194/acp16-2971-2016, 2016.

Mainelis, G., Berry, D., An, H. R., Yao, M. S., DeVoe, K., Fennell, D. E., and Jaeger, R.: Design and performance of a single-pass bubbling bioaerosol generator, Atmos. Environ., 39, 3521-3533, https://doi.org/10.1016/j.atmosenv.2005.02.043, 2005.

Mason, R. H., Si, M., Li, J., Chou, C., Dickie, R., Toom-Sauntry, D., Pöhlker, C., Yakobi-Hancock, J. D., Ladino, L. A., Jones, K., Leaitch, W. R., Schiller, C. L., Abbatt, J. P. D., Huffman, J. A., and Bertram, A. K.: Ice nucleating particles at a coastal marine boundary layer site: correlations with aerosol type and meteorological conditions, Atmos. Chem. Phys., 15, 12547-12566, https://doi.org/10.5194/acp-15-12547-2015, 2015.

McKnight, D. M., Andrews, E. D., Spaulding, S. A., and Aiken, G. R.: Aquatic fulvic-acids in algal-rich antarctic ponds, Limnol. Oceanogr., 39, 1972-1979, 1994.

Mercier, X., Faccinetto, A., and Desgroux, P.: Cleaner Combustion: Developing Detailed Chemical Kinetic Models, Green Energy and Technology, Springer, London, 2013.

Möhler, O., DeMott, P. J., Vali, G., and Levin, Z.: Microbiology and atmospheric processes: the role of biological particles in cloud physics, Biogeosciences, 4, 1059-1071, https://doi.org/10.5194/bg-4-1059-2007, 2007

Morris, C. E., Georgakopoulos, D. G., and Sands, D. C.: Ice nucleation active bacteria and their potential role in precipitation, J. Physique IV, 121, 87-103, https://doi.org/10.1051/jp4:2004121004, 2004.

Niessner, R. and Krupp, A.: Detection and chemical characterization of polycyclic aromatic hydrocarbon aerosols by means of laser-induced fluorescence, Part. Part. Syst. Char., 8, 23-28, https://doi.org/10.1002/ppsc.19910080106, 1991.

O'Connor, D. J., Daly, S. M., and Sodeau, J. R.: Online monitoring of airborne bioaerosols released from a composting/green waste site, Waste Manage., 42, 23-30, https://doi.org/10.1016/j.wasman.2015.04.015, 2015a.

O'Connor, D. J., Healy, D. A., and Sodeau, J. R.: A 1-month online monitoring campaign of ambient fungal spore concentrations in the harbour region of Cork, Ireland, Aerobiologia, 31, 295-314, https://doi.org/10.1007/s10453-015-9365-7, $2015 \mathrm{~b}$.

Pan, Y. L., Holler, S., Chang, R. K., Hill, S. C., Pinnick, R. G., Niles, S., Bottiger, J. R., and Bronk, B. V.: Real-time detection and characterization of individual flowing airborne biological particles: fluorescence spectra and elastic scattering measurements, P. Soc. Photo-Opt. Ins., 3855, 117-125, 1999.

Panne, U., Knoller, A., Kotzick, R., and Niessner, R.: On-line and in-situ detection of polycyclic aromatic hydrocarbons (PAH) on aerosols via thermodesorption and laser-induced fluorescence spectroscopy, Fresen. J. Anal. Chem., 366, 408-414, 2000.

Penner, J. E.: Carbonaceous aerosols influencing atmospheric radiation:black and organic carbon, in Aerosol Forcing of Climate, edited by: Charlson, R. J. and Heitzenberg, J., Wiley, New York, 91-108, 1995.
Perring, A. E., Schwarz, J. P., Baumgardner, D., Hernandez, M. T., Spracklen, D. V., Heald, C. L., Gao, R. S., Kok, G., McMeeking, G. R., McQuaid, J. B., and Fahey, D. W.: Airborne observations of regional variation in fluorescent aerosol across the United States, J. Geophys. Res.-Atmos., 120, 1153-1170, https://doi.org/10.1002/2014JD022495, 2015.

Pinnick, R. G., Hill, S. C., Nachman, P., Pendleton, J. D., Fernandez, G. L., Mayo, M. W., and Bruno, J. G.: Fluorescence Particle Counter for Detecting Airborne Bacteria and Other Biological Particles, Aerosol Sci. Tech., 23, 653-664, 1995.

Pöhlker, C., Huffman, J. A., and Pöschl, U.: Autofluorescence of atmospheric bioaerosols - fluorescent biomolecules and potential interferences, Atmos. Meas. Tech., 5, 37-71, https://doi.org/10.5194/amt-5-37-2012, 2012.

Pöhlker, C., Huffman, J. A., Förster, J.-D., and Pöschl, U.: Autofluorescence of atmospheric bioaerosols: spectral fingerprints and taxonomic trends of pollen, Atmos. Meas. Tech., 6, 3369-3392, https://doi.org/10.5194/amt-6-3369-2013, 2013.

Pöschl, U.: Atmospheric aerosols: Composition, transformation, climate and health effects, Angew. Chem. Int. Edit., 44, 7520 7540, https://doi.org/10.1002/anie.200501122, 2005.

Pöschl, U., Martin, S. T., Sinha, B., Chen, Q., Gunthe, S. S., Huffman, J. A., Borrmann, S., Farmer, D. K., Garland, R. M., Helas, G., Jimenez, J. L., King, S. M., Manzi, A., Mikhailov, E., Pauliquevis, T., Petters, M. D., Prenni, A. J., Roldin, P., Rose, D., Schneider, J., Su, H., Zorn, S. R., Artaxo, P., and Andreae, M. O.: Rainforest Aerosols as Biogenic Nuclei of Clouds and Precipitation in the Amazon, Science, 329, 15131516, https://doi.org/10.1126/science.1191056, 2010.

Powelson, M. H., Espelien, B. M., Hawkins, L. N., Galloway, M. M., and De Haan, D. O.: Brown Carbon Formation by Aqueous-Phase Carbonyl Compound Reactions with Amines and Ammonium Sulfate, Environ. Sci. Technol., 48, 985-993, https://doi.org/10.1021/es4038325, 2014.

Primmerman, C.: Detection of biological agents, Lincoln Laboratory Journal, Vol. 12, 2000.

Robinson, E. S., Gao, R.-S., Schwarz, J. P., Fahey, D. W., and Perring, A. E.: Fluorescence calibration method for single-particle aerosol fluorescence instruments, Atmos. Meas. Tech., 10, 17551768, https://doi.org/10.5194/amt-10-1755-2017, 2017.

Ruske, S., Topping, D. O., Foot, V. E., Kaye, P. H., Stanley, W. R., Crawford, I., Morse, A. P., and Gallagher, M. W.: Evaluation of machine learning algorithms for classification of primary biological aerosol using a new UV-LIF spectrometer, Atmos. Meas. Tech., 10, 695-708, https://doi.org/10.5194/amt-10-6952017, 2017.

Saari, S., Mensah-Attipoe, J., Reponen, T., Veijalainen, A. M., Salmela, A., Pasanen, P., and Keskinen, J.: Effects of fungal species, cultivation time, growth substrate, and air exposure velocity on the fluorescence properties of airborne fungal spores, Indoor Air, 25, 653-661, https://doi.org/10.1111/ina.12166, 2015a.

Saari, S., Niemi, J. V., Ronkko, T., Kuuluvainen, H., Jarvinen, A., Pirjola, L., Aurela, M., Hillamo, R., and Keskinen, J.: Seasonal and Diurnal Variations of Fluorescent Bioaerosol Concentration and Size Distribution in the Urban Environment, Aerosol Air Qual. Res., 15, 572-581, https://doi.org/10.4209/aaqr.2014.10.0258, 2015b. 
Sivaprakasam, V., Huston, A., Scotto, C., and Eversole, J.: Multiple UV wavelength excitation and fluorescence of bioaerosols, Opt. Express, 12, 4457-4466, 2004.

Sivaprakasam, V., Lin, H. B., Huston, A. L., and Eversole, J. D.: Spectral characterization of biological aerosol particles using two-wavelength excited laser-induced fluorescence and elastic scattering measurements, Opt. Express, 19, 6191-6208, https://doi.org/10.1364/oe.19.006191, 2011.

Slowik, J. G., Cross, E. S., Han, J. H., Kolucki, J., Davidovits, P., Williams, L. R., Onasch, T. B., Jayne, J. T., Kolb, C. E., and Worsnop, D. R.: Measurements of morphology changes of fractal soot particles using coating and denuding experiments: Implications for optical absorption and atmospheric lifetime, Aerosol Sci. Tech., 41, 734-750, https://doi.org/10.1080/02786820701432632, 2007.

Sodeau, J. R. and O'Connor, D. J.: Chap. 16 - Bioaerosol Monitoring of the Atmosphere for Occupational and Environmental Purposes, in: Comprehensive Analytical Chemistry, The Quality of Air, Elsevier, 391-420, 2016.

Taketani, F., Kanaya, Y., Nakamura, T., Koizumi, K., Moteki, N., and Takegawa, N.: Measurement of fluorescence spectra from atmospheric single submicron particle using laserinduced fluorescence technique, J. Aerosol Sci., 58, 1-8, https://doi.org/10.1016/j.jaerosci.2012.12.002, 2013.

Toprak, E. and Schnaiter, M.: Fluorescent biological aerosol particles measured with the Waveband Integrated Bioaerosol Sensor WIBS-4: laboratory tests combined with a one year field study, Atmos. Chem. Phys., 13, 225-243, https://doi.org/10.5194/acp13-225-2013, 2013.

Twohy, C. H., McMeeking, G. R., DeMott, P. J., McCluskey, C. S., Hill, T. C. J., Burrows, S. M., Kulkarni, G. R., Tanarhte, M., Kafle, D. N., and Toohey, D. W.: Abundance of fluorescent biological aerosol particles at temperatures conducive to the formation of mixed-phase and cirrus clouds, Atmos. Chem. Phys., 16, 8205-8225, https://doi.org/10.5194/acp-16-8205-2016, 2016.

Valsan, A. E., Ravikrishna, R., Biju, C. V., Pöhlker, C., Després, V. R., Huffman, J. A., Pöschl, U., and Gunthe, S. S.: Fluorescent biological aerosol particle measurements at a tropical high-altitude site in southern India during the southwest monsoon season, Atmos. Chem. Phys., 16, 9805-9830, https://doi.org/10.5194/acp16-9805-2016, 2016.

Von Helden, G., Hsu, M. T., Gotts, N., and Bowers, M. T.: Carbon cluster cations with up to 84 atoms - structures, formation mechanism, and reactivity, J. Phys. Chem., 97, 8182-8192, https://doi.org/10.1021/j100133a011, 1993.

Whitehead, J. D., Gallagher, M. W., Dorsey, J. R., Robinson, N., Gabey, A. M., Coe, H., McFiggans, G., Flynn, M. J., Ryder, J., Nemitz, E., and Davies, F.: Aerosol fluxes and dynamics within and above a tropical rainforest in South-East Asia, Atmos. Chem. Phys., 10, 9369-9382, https://doi.org/10.5194/acp10-9369-2010, 2010.
Whitehead, J. D., Darbyshire, E., Brito, J., Barbosa, H. M. J., Crawford, I., Stern, R., Gallagher, M. W., Kaye, P. H., Allan, J. D., Coe, H., Artaxo, P., and McFiggans, G.: Biogenic cloud nuclei in the central Amazon during the transition from wet to dry season, Atmos. Chem. Phys., 16, 9727-9743, https://doi.org/10.5194/acp-16-9727-2016, 2016.

Wright, T. P., Hader, J. D., McMeeking, G. R., and Petters, M. D.: High Relative Humidity as a Trigger for Widespread Release of Ice Nuclei, Aerosol Sci. Tech., 48, https://doi.org/10.1080/02786826.2014.968244, 2014.

Wu, Y., Chen, A. L., Luhung, I., Gall, E. T., Cao, Q. L., Chang, V. W. C., and Nazaroff, W. W.: Bioaerosol deposition on an air-conditioning cooling coil, Atmos. Environ., 144, 257-265, https://doi.org/10.1016/j.atmosenv.2016.09.004, 2016.

Xie, Y. Y., Fajardo, O. A., Yan, W. Z., Zhao, B., and Jiang, J. K.: Six-day measurement of size-resolved indoor fluorescent bioaerosols of outdoor origin in an office, Particuology, 31, 161169, https://doi.org/10.1016/j.partic.2016.09.004, 2017.

Yu, X., Wang, Z., Zhang, M., Kuhn, U., Xie, Z., Cheng, Y., Pöschl, U., and Su, H.: Ambient measurement of fluorescent aerosol particles with a WIBS in the Yangtze River Delta of China: potential impacts of combustion-related aerosol particles, Atmos. Chem. Phys., 16, 11337-11348, https://doi.org/10.5194/acp-16-113372016, 2016.

Zelenyuk, A., Cai, Y., and Imre, D.: From agglomerates of spheres to irregularly shaped particles: Determination of dynamic shape factors from measurements of mobility and vacuum aerodynamic diameters, Aerosol Sci. Tech., 40, 197-217, https://doi.org/10.1080/02786820500529406, 2006.

Zhen, H., Han, T., Fennell, D., and Mainelis, G.: A systematic comparison of four bioaerosol generators: Effect on culturability and membrane integrity when aerosolizing E. coli bacteria, A systematic comparison of four bioaerosol generators: Effect on culturability and membrane integrity when aerosolizing E. coli bacteria, J. Aerosol Sci., 70, 67-79, 2014.

Ziemba, L. D., Beyersdorf, A. J., Chen, G., Corr, C. A., Crumeyrolle, S. N., Diskin, G., Hudgins, C., Martin, R., Mikoviny, T., Moore, R., Shook, M., Thornhill, K. L., Winstead, E. L., Wisthaler, A., and Anderson, B. E.: Airborne observations of bioaerosol over the Southeast United States using a Wideband Integrated Bioaerosol Sensor, J. Geophys. Res.-Atmos., 121, 85068524, https://doi.org/10.1002/2015JD024669, 2016. 